\title{
Tax Structure and Government Expenditures under Tax Equity Norms
}

\author{
Tobias König \\ Andreas Wagener
}

CESIFO WORKING PAPER No. 3205

CATEgory 1: Public FinANCE

OCTOBER 2010

\footnotetext{
An electronic version of the paper may be downloaded

- from the SSRN website: www.SSRN.com

- from the RePEc website: - from the CESifo website: 


\title{
Tax Structure and Government Expenditures under Tax Equity Norms
}

\begin{abstract}
We augment a standard tax model by concerns about tax equity: people get upset when labour is taxed more heavily than capital. Even the slightest concern for tax equity invalidates the common recommendation for small open economies that capital should remain tax-exempt. This holds for exogenous as well as for endogenous government expenditures and irrespective of whether concerns with tax equity only cause emotional discomfort or also impact on work incentives. If concerns with tax equity get more intense, the economy may choose higher taxes on labour and move to the downward sloped part of its Laffer curve. For endogenous government spending, stronger concerns with tax equity may call for a larger size of the public sector.
\end{abstract}

JEL-Code: H20, E62, P16, Z10.

Keywords: justice, fairness, taxation, policy mix.

Tobias König

Department of Economics and Management

Leibniz University of Hannover

Koenigsworther Platz 1

Germany - 30167 Hannover

koenig@sopo.uni-hannover.de
Andreas Wagener

Department of Economics and Management

Leibniz University of Hannover

Koenigsworther Platz 1

Germany - 30167 Hannover

wagener@sopo.uni-hannover.de

The authors thank Thomas Gaube, Robert Schwager, Matthias Wrede, Panu Poutvaara, and conference and seminar participants in Athens, Barcelona, Istanbul, Marburg, Magdeburg, Las Vegas, and Venice for helpful comments and suggestions on an earlier draft. The usual disclaimer applies. 


\section{Introduction}

A fundamental theorem on taxation states that small open economies should not rely on capital taxation. This result, originally derived in Gordon (1986), emerges from the assumption of an infinitely elastic capital supply which small countries face. Under this assumption, the burden of a tax on capital will be entirely shifted onto workers or other immobile domestic factors. But if those factors bear the tax burden anyway, it is less costly to tax them directly and, by this, to avoid the excess burden associated with capital flight.

Zero capital taxation, thus, is optimal in this class of models - it maximizes the representative household's utility and is also the policy outcome that people actually want and would vote for. However, in reality the prospect of zero taxes on capital hardly looks popular. It flies in the face of all sorts of concerns with equity, fairness, and equal treatment in taxation - which remain unmodelled in the standard framework of optimal (international) taxation. Over the past decades a large body of evidence has been compiled suggesting that people not only care for, or are solely driven by, material self-interest but also by values, norms and equity concerns. Such ethical preferences have been embedded into various economic contexts, but only little is known about the optimal tax structure when ethical norms are related to taxation.

In this paper, we analyse optimal taxation in the presence of tax equity norms, i.e., when citizens hold the view that tax rates on capital and labour incomes ought not to differ too widely. Such an approach can be motivated along several lines:

- First, tax systems that exclusively or disproportionately rely on taxes on labour incomes appear unacceptable on grounds of common norms for equity and justice. ${ }^{1}$ The most general and fundamental of such norms is reflected in the principle of horizontal tax equity, to which most tax systems pay at least lip service. Stating that equal incomes should be taxed at equal rates (Musgrave, 1959; Kaplow, 1995), the principle forms part of the rationale underlying the comprehensive income tax (of the Schanz-Haig-Simons type), a normative ideal to which many countries (used to) adhere. ${ }^{2}$ Discrimination between similarly situated tax payers - such as zero or low taxes on capital in the presence of positive and high tax rates on labour - clearly violates this principle. Such discrimination also violates its relative, the ability-to-pay principle, stating that all members of society have a duty to pay taxes in accordance with their economic capabilities; tax legislation warps this principle when tax privileges are not based on ability to pay. ${ }^{3}$

\footnotetext{
${ }^{1}$ For a survey on tax equity norms and their implications for actual tax policy see, e.g., Barker (2006).

${ }^{2}$ These aspects also matter in the debate on dual income taxes: by applying different tax treatments to incomes from different sources, dual income tax generate problems of horizontal inequity. See, e.g., Sørensen (1994).

${ }^{3}$ Moreover, burdening only one subgroup of the population (i.e., workers) could also be in conflict with the benefit principle of taxation, stating that the taxes an agent pays should somehow reflect the benefits that (s)he receives from the goods and services supplied by the state (for a discussion of the benefit and sacrifice principles of
} 
- Second, equity does not only matter from the abstract perspective of a philosopher. Rather, the experimental literature provides ample evidence that perceptions of "fairness" and its violation indeed and significantly impact on individuals' subjective well-being as well as on individuals' behaviour (for a survey see Fehr and Schmidt, 2006). From a citizen's perspective equity constitutes an important criterion for the legitimacy of a tax system; it shapes tax compliance (Bordignon, 1993), political support (Taylor, 2003, p. 84) and work incentives. Boadway et al. (2007) argue that individuals hold personal views on what constitutes an ethical tax rate; discrepancies between actual and ethically acceptable tax rates may induce individuals to (legally) avoid taxation by adjusting their labour supply. Hence, hurt ethical feelings may give rise to tax distortions.

- Third, zero or low tax rates on capital income in the presence of high tax rates on labour income cause discontent and envy. The rich, capital income earners or profitable businesses getting away without being taxed adequately makes wage earners with (perceived) high tax burdens angry (The Economist, 2009). The "common man", paying a substantial share of his moderate income in taxes, is upset when - as it happens in many countries capital incomes are subject to rather symbolic income or capital gains taxes, exempt from contributing to social insurance, and given various preferences and privileges. Likewise, the (perception of a) growing imbalance in the taxation of labour and capital incomes (allegedly induced by globalisation) nourishes political discomfort. Generally, policies that discriminate across comparable circumstances or individuals appear to create resentment, possibly also endangering social stability. This view finds strong support in the sociopsychological literature which shows that relative deprivation - via unequal treatment, exclusion, or discrimination - negatively impacts both on individual well-being and on social cohesion and welfare (Runciman, 1966; Podder, 1996). ${ }^{4}$ As argued by Elster (1991, p. 66) in general and by Boskin and Sheshinski (1978, p. 590) for taxation, a society that tries to assuage its envy may well adopt policies that damage its material interests.

- Fourth, large discrepancies between taxes on capital and labour may indicate a high degree of inequality which might be detrimental for utility (Alesina and Angeletos, 2005). Reducing inequality is a major rationale for taxation in modern societies, and the exemption from taxation or low tax rates for capital incomes and fortunes let the social compact for redistribution appear shaky - which many people find undesirable (Brooks and Manza 2006). Concerns over inequality have mainly been studied in the context of the progressiv-

taxation see, e.g., Neill, 2000). Since everybody benefits from the provision of public goods, the benefit principle calls (as a minimum) for a positive share in taxes for everyone.

${ }^{4}$ While economists tend to reduce relative deprivation to shortfalls of income or consumption, Runciman's original concept is far wider and applicable to abstract or intangible social objects, including policy measures such as tax rates. 
ity of income taxes (see, e.g., Snyder and Kramer, 1988). Recently, however, Kim (2007) embedded fairness considerations in form of inequality aversion into a Ramsey-Mirrlees framework of optimal taxation, making the case for a substantial taxation of capital. ${ }^{5}$

To summarize, people seem to care about the tax structure in itself (and beyond the extent by which it affects their own net incomes). They find it important that tax rates on different factors or types of income do not differ too much. Tax rate differentials affect individual well-being via concerns for equity, equality, and sentiments of relative deprivation or envy. In this paper we analyze the implications of such concerns for the tax structures in small open economies. To keep terminology simple, we shall henceforth and invariably refer to tax-related sentiments as "tax equity concerns". This term is an imperfect container for a wide range of different concepts that partially overlap and are difficult to disentangle (norms for horizontal tax equity, envy, fairness perceptions, feelings of relative deprivation or discrimination, status concerns etc.). Their common denominator is, however, that large discrepancies between tax rates on different types of income are undesirable. From a modelling perspective, holding a tax equity norms mean that tax rates (or the tax structure) directly into one's utility function, independently of whether material well-being is affected or not.

Concerns for tax equity may matter in at least two different ways: Perceiving a situation as more inequitable may cause discomfort and reduce the level of well-being (level effect), but it may also trigger adjustments in labour supply (incentive effects). The motivation for the inclusion of incentive effetcs comes from empirical and experimental evidence suggesting that unfairness felt in the context of taxation indeed affects work incentives. Dissatisfied individuals spend less effort on work, show higher rates of absenteeism etc. (see, e.g., Lévy-Garboua et al., 2009; Cornelissen et al., 2010, or in a theoretical framework, Boadway et al., 2007). In social psychology, adverse behavioural reactions of this type have since long been discussed under the label "equity theory" (Adams, 1963). In our model, level effects of tax equity concerns formally show up in preferences as (separable) reductions in total utility while incentive effects affect marginal rates of substitution between consumption and leisure.

We embed these tax equity concerns into a model of a small open economy whose remaining components are fairly standard: A single output is produced with labour and capital. Capital is perfectly mobile internationally. Workers are immobile but their supply of labour is endogenous (and may be affected by equity concerns). Higher levels of capital imply higher equilibrium

\footnotetext{
${ }^{5}$ Another potential argument why unequal tax rates are disliked may indirectly enter via relative-income concerns (Luttmer, 2005; Layard 2006). If individual well-being depends, in addition to the absolute level of own income, also on one's income position relative to others and taxation changes these relative positions, then tax privileges (for earners of capital income, say) may be detrimental to utility (of wage earners, say). We do not follow this route here. With status concerns, the reference point for the assessment of taxes is not a general standard but an interpersonal comparison whose normative relevance is unclear.
} 
wages. The government provides a consumption good and finances its expenditures with linear source taxes on capital and labour income. The level of government expenditure can be exogenously given or might be chosen optimally.

In the absence of concerns for tax equity, government finance should exclusively rely on labour income taxes. Capital taxation causes a higher excess burden, irrespectively of whether government expenditures are exogenous or endogenous. An optimum without concerns for tax equity, thus, involves a large differential tax treatment of capital and labour.

In the presence of equity concerns, however, the tax designer faces a trade-off. On the one hand, there is the standard excess burden: taxes on capital drive capital out of the country and, by this, also depress gross wages. On the other hand, at given (and relatively high) labour tax rates, they reduce the tax gap and thereby placate equity concerns. This trade-off has a number of implications for optimal tax policies, some expected, some perhaps less so.

First, exempting capital income from taxation is never optimal. Already with the slightest concern for tax equity a zero tax rate on capital income ceases to be optimal, irrespectively of whether equity concerns impact on work incentives or "only" on well-being. Second, and more surprising, stronger concerns for tax equity may indeed call for a higher level of labour taxation. One reason is that equity concerns may drive the economy onto the decreasing part of the partial Laffer curve for the capital tax - a situation that would never occur within a standard framework of taxation. Another reason is that government finance via capital taxes may eventually carry so large an excess burden that a further increase of capital taxes, induced by stronger equity concerns, needs to be accommodated by an (smaller) increase in labour taxes. Third, also the comparative statics for government expenditures reveal some interesting non-monotonicities. One might expect that a stronger concern for tax equity calls for higher capital tax rates and, by this, for a smaller public sector (capital taxation being plagued by a larger excess burden). However, even when the former is true, the size of the public sector need not necessarily decline. Tax equity concerns erode the size of the public sector only when they are relatively weak. If strong equity concerns grow even more intense, higher government expenditure can be desirable. Our paper contributes to the theory of taxation in two areas. First, it complements a small literature that incorporates values and equity norms into optimal tax frameworks. ${ }^{6}$ Most of this literature is concerned with the impact of equity perceptions on tax compliance, but some recent theoretical and experimental research also deals with the interaction between inequity aversion (in the Fehr-Schmidt sense) and tax structures (see, e.g., Kim 2007, or Lévy-Garboua et al., 2009). Second, we add to recent research on the optimal mix of capital and labour taxation in

\footnotetext{
${ }^{6}$ The literature on social preferences often assumes that individuals compare their own income position to that of others. If such comparisons entail negative externalities (via envy, say), Pigouvian taxes may be helpful remedies (see, e.g., Alvarez-Cuadrado 2007; Alonso-Carrera et al. 2006). By contrast, in our framework unequal taxation is a source of disutility - and not a remedy against it.
} 
open economies which is puzzled by the failure of empirical studies to confirm the theoretical prediction that increased capital mobility leads to a lower relative tax burden on capital (see Haufler, 1997, or Haufler et al., 2008). Our paper suggests that concerns with tax equity may have prevented such a race to the bottom for capital taxes; the social value of balanced taxation may outweigh the economic benefits from low capital taxes.

This paper proceeds as follows: Section 2 sets out a basic model with tax equity concerns. In Section 3, we analyze tax policies and their comparative statics for the case that government spending is exogenous. In Section 4, we extend the model to endogenous government spending. Section 5 concludes.

\section{The model}

We consider a small open one-good economy which is inhabited by a large number of identical individuals. For simplicity, we normalize the number of individuals to unity. Production in the economy takes place in one single-output firm that is owned by absent foreigners. It uses labour and capital as its inputs. Capital is an internationally mobile factor of production that can be purchased on world capital markets at an exogenous rental rate of $r>0$ per unit. Capital and labour can be taxed with constant average tax rates $t_{\ell}$ for labour and $t_{k}$ for capital. Taxation is only source-based.

The individual has convex and increasing preferences over consumption $c$, leisure - which will be negatively represented by working hours $\ell-$, and a publicly provided good $g$. We assume that these preferences can be represented by an additively separable utility function

$$
u(c, \ell)=c-E(\ell, \psi)+h(g)-\Omega,
$$

where $E(\cdot)$ with $E_{\ell}>0$ and $E_{\ell \ell}>0$ represents the disutility from labour $\ell$ and $h(g)$ with $h^{\prime}(g)>0>h^{\prime \prime}(g)$ measures the utility from the publicly provided good.

The special features of preferences in our model are functions $\Omega$ and $\psi$, both of which are assumed to depend on the tax rates on labour and capital:

$$
\Omega=\Omega\left(t_{\ell}, t_{k}\right) \quad \text { and } \quad \psi=\psi\left(t_{\ell}, t_{k}\right) .
$$

Preferences, thus, directly depend on the policy choices made in the society. Specifically, $\Omega$ captures that the level of individual well-being may be affected by the tax structure. We assume that

$$
\Omega_{\ell}:=\partial \Omega / \partial t_{\ell} \geq 0 \quad \text { and } \quad \Omega_{k}:=\partial \Omega / \partial t_{k} \leq 0
$$

Hence, individuals welcome lower taxes on labour and higher taxes on capital. In spite of this asymmetric treatment of $t_{k}$ and $t_{\ell}$ in $\Omega$ (and also below in $\psi$ ), we can interpret $\Omega$ (and $\psi$ ) as concerns for tax equity. In our framework, we will only encounter situations where capital is 
taxed less severely than labour. On this domain, preference functions such as $\Omega$ can reflect that any widening of the statutory tax gap $\left(t_{\ell}-t_{k}\right)$ is welfare reducing. Viz., as a special case (sometimes used below), $\Omega$ could be written as

$$
\Omega=\tilde{\Omega}\left(\beta \cdot\left(t_{\ell}-t_{k}\right)\right)
$$

with $\tilde{\Omega}^{\prime}>0$; the parameter $\beta>0$ would then measure the intensity of the equity concern.

The function $\psi$ in (1) captures that tax equity concerns may generate incentive effects: the disutility from work not only varies with working hours $\ell$ but also with the individual's perception $\psi$ of tax policies. We assume that both the absolute and the marginal disutility from labour increases whenever the tax policy is perceived to be less fair $\left(E_{\psi}>0, E_{\ell \psi}>0\right)$. Moreover, we assume that $\psi=\psi\left(t_{\ell}, t_{k}\right)$ with

$$
\psi_{\ell}:=\partial \psi / \partial t_{\ell} \geq 0 \quad \text { and } \quad \psi_{k}:=\partial \psi / \partial t_{k} \leq 0
$$

reflecting that higher taxes on labour (weakly) depress work morale while higher taxes on capital boost it. As with $\Omega$, this asymmetric treatment does not preclude the interpretation of $\psi$ as an ethical norm; we operate on a policy domain where $t_{k}<t_{\ell}$. Experimental evidence for the validity of (2) can be found in Lévy-Garboua et al. (2009) where it is shown that workers who consider equity norms to be violated by taxation refuse to work.

As discussed in the introduction, the labelling of both $\psi$ and $\Omega$ as equity concerns covers a wide array of affects, ranging from abstract horizontal equity norms to envy to feelings of relative deprivation. The distinction between $\Omega$ and $\psi$ reflects two channels of tax equity: a work morale effect ( $\psi$ alters the marginal rate of substitution between leisure and consumption) and a "feel-good" effect ( $\Omega$ affects well-being but leaves incentives untouched).

In (1) we take the perspective of a worker without capital income. Moreover, (1) does not entail any status concerns, comparisons with reference groups or comparisons of actual tax payments; the direct preference over tax structures is purely an (individual) ethic norm.

The legal incidence of labour taxes is assumed to lie with workers. Thus, the disposable income of a worker just equals the hourly net wage $\left(w-t_{\ell}\right)$ times hours worked: $c=\left(w-t_{\ell}\right) \cdot \ell$. The (gross) wage rate $w$ will be endogenously determined (see below).

Individuals take the wage and tax rate as parametrically given when deciding on their labour supply. Substituting for $c$ in (1) and maximizing over $\ell$ requires that:

$$
E_{\ell}\left(\ell, \psi\left(t_{\ell}, t_{k}\right)\right)=w-t_{\ell}
$$


Equation (3) implicitly defines a labour supply function $\ell^{S}\left(w, t_{\ell}, t_{k}\right)$ with properties

$$
\begin{aligned}
\frac{\partial \ell^{S}}{\partial w} & =\frac{1}{E_{\ell \ell}}>0, \\
\frac{\partial \ell^{S}}{\partial t_{\ell}} & =-\frac{1}{E_{\ell \ell}} \cdot\left(1+E_{\ell \psi} \cdot \psi_{\ell}\right)<0, \\
\frac{\partial \ell^{S}}{\partial t_{k}} & =-\frac{E_{\ell \psi}}{E_{\ell \ell}} \cdot \psi_{k}>0 .
\end{aligned}
$$

Firms maximize their profits. Denoting by $K$ and $L$, respectively, the amounts of capital and labour employed in the firm, output of the firm equals $F(K, L)$, where $F$ is a strictly increasing, constant-returns-to-scale and strictly quasi-concave production function. Firms pay a tax $t_{k}$ on each unit of capital they hire. Since the cost of hiring an additional hour of labour are $w$ while an additional unit of capital costs $r+t_{k}$, the firm's net profits amount to

$$
\pi=F(K, L)-w \cdot L-\left(r+t_{k}\right) \cdot K=L \cdot\left(f(k)-w-\left(r+t_{k}\right) \cdot k\right) .
$$

Here, $k:=K / L$ denotes capital per labour unit and $f(k)$ is the per-unit-of-labour production function; $f$ is strictly increasing and strictly concave. The firm takes input prices and taxes as given. Profit maximization requires

$$
f^{\prime}(k)=r+t_{k},
$$

which implicitly defines the capital intensity $k=k\left(r+t_{k}\right)$ as a function of the cost of capital, with

$$
k^{\prime}\left(r+t_{k}\right)=\frac{1}{f^{\prime \prime}(k)}<0 .
$$

Since we assume constant returns to scale, the gross wage rate is determined via the factor price frontier and is given by

$$
w\left(r+t_{k}\right)=f(k)-(r+t) \cdot k
$$

with

$$
w^{\prime}\left(r+t_{k}\right)=-k
$$

In equilibrium, labour supply must equal labour demand. The equilibrium level $L^{*}$ of employment is, thus, given by

$$
L^{*}\left(t_{\ell}, t_{k}\right)=\ell^{S}\left(w\left(r+t_{k}\right), t_{\ell}, t_{k}\right)
$$

it decreases in the tax rate on labour but has an ambiguous response to higher capital taxation:

$$
\begin{aligned}
& \frac{\partial L^{*}}{\partial t_{\ell}}=\frac{\partial \ell^{S}}{\partial t_{\ell}}<0, \\
& \frac{\partial L^{*}}{\partial t_{k}}=w^{\prime}\left(r+t_{k}\right) \cdot \frac{\partial \ell^{S}}{\partial w}+\frac{\partial \ell^{S}}{\partial t_{k}}=-k \cdot \frac{\partial \ell^{S}}{\partial w}+\frac{\partial \ell^{S}}{\partial t_{k}} \lesseqgtr 0 .
\end{aligned}
$$


Note that when equity concerns are sufficiently high, they may offset the usual disincentive from higher capital taxation on labour supply. In this case, equilibrium employment would increase in the tax rate on labour.

The government provides a (public) good $g$ (measured in units of output) which has to be financed out of the revenues from labour and capital taxes. Hence, its budget constraint reads:

$$
g=t_{\ell} \cdot L^{*}+t_{k} \cdot K=L^{*}\left(t_{\ell}, t_{k}\right) \cdot\left(t_{\ell}+t_{k} \cdot k\left(r+t_{k}\right)\right)=: G\left(t_{\ell}, t_{k}\right) .
$$

In what follows, we shall refer to $G\left(t_{\ell}, t_{k}\right)$ as the Laffer curve of the economy. For later use, we note that from (13) the partial derivatives of the Laffer curve with respect to the two tax rates are given by

$$
\begin{aligned}
& \frac{\partial G}{\partial t_{k}}=\frac{\partial L^{*}}{\partial t_{k}} \cdot\left(t_{\ell}+t_{k} k\right)+L^{*} \cdot\left(k+t_{k} k^{\prime}\right)=: G_{k}, \\
& \frac{\partial G}{\partial t_{\ell}}=\frac{\partial L^{*}}{\partial t_{\ell}} \cdot\left(t_{\ell}+t_{k} k\right)+L^{*}=: G_{\ell} .
\end{aligned}
$$

\section{$3 \quad$ Optimal tax policy with exogenous government spending}

In this section, we assume that a given and fixed level of government revenues $\bar{g}$ has to be raised; the case of endogenous government expenditures will be dealt with in Section 4 .

\subsection{Some taxation of capital is optimal}

The government chooses $t_{\ell}$ and $t_{k}$ such as to maximize individual welfare (recall that firm owners are absentee capitalists). Plugging the equilibrium level of employment $L^{*}$ and (13) into (1) and taking into account that $w=w\left(r+t_{k}\right)$ via (10), we obtain indirect utility (= social welfare) in equilibrium as follows:

$$
V\left(t_{\ell}, t_{k}\right):=\left(w\left(r+t_{k}\right)-t_{\ell}\right) \cdot L^{*}\left(t_{\ell}, t_{k}\right)-E\left(L^{*}\left(t_{\ell}, t_{k}\right), \psi\left(t_{\ell}, t_{k}\right)\right)-\Omega\left(t_{\ell}, t_{k}\right) .
$$

As government expenditures $g$ are exogenously fixed, the utility $h(g)$ derived from them does not matter here; it is omitted from (16). The government chooses tax rates $t_{\ell}$ and $t_{k}$ such as to maximize $V$ subject to the revenue constraint. The Lagrangian $W$ for this problem reads:

$$
\max _{t_{\ell}, t_{k}} W\left(t_{\ell}, t_{k}\right)=V\left(t_{\ell}, t_{k}\right)+\lambda \cdot\left[G\left(t_{\ell}, t_{k}\right)-\bar{g}\right],
$$

where $\lambda$ denotes the Lagrange multiplier and $\bar{g}$ the exogenous level of the public good to be financed. Differentiating (17), with respect to tax rates $\left(t_{k}, t_{\ell}\right)$ and using the Envelope Theorem 
gives:

$$
\begin{aligned}
\frac{\partial W}{\partial t_{\ell}} & =-L^{*}+\lambda \cdot G_{\ell}-E_{\psi} \cdot \psi_{\ell}-\Omega_{\ell} \\
& =L^{*} \cdot[\lambda-1]+\lambda \cdot\left(t_{\ell}+t_{k} k\right) \cdot \frac{\partial L^{*}}{\partial t_{\ell}}-E_{\psi} \cdot \psi_{\ell}-\Omega_{\ell} \\
\frac{\partial W}{\partial t_{k}} & =w^{\prime}\left(r+t_{k}\right) L^{*}+\lambda \cdot G_{k}-E_{\psi} \cdot \psi_{k}-\Omega_{k} \\
& =k L^{*} \cdot[\lambda-1]+\lambda \cdot\left(\left(t_{\ell}+t_{k} k\right) \cdot \frac{\partial L^{*}}{\partial t_{k}}+t_{k} k^{\prime} L^{*}\right)-E_{\psi} \cdot \psi_{k}-\Omega_{k} .
\end{aligned}
$$

No concerns for tax equity. As a benchmark, we consider the case without tax equity concerns (i.e., $\psi_{k}=\psi_{\ell}=\Omega_{k}=\Omega_{\ell} \equiv 0$ ). Here,

$$
\frac{\partial L^{*}}{\partial t_{\ell}}=-\frac{\partial \ell^{S}}{\partial w} \text { and } \quad \frac{\partial L^{*}}{\partial t_{k}}=-k \cdot \frac{\partial \ell^{S}}{\partial w} .
$$

From (18) and (19) we, thus, get

$$
\frac{\partial W}{\partial t_{\ell}}=\frac{1}{k} \cdot \frac{\partial W}{\partial t_{k}}-\lambda L^{*} \frac{t_{k} k^{\prime}}{k}>\frac{1}{k} \cdot \frac{\partial W}{\partial t_{k}}
$$

for all $\left(t_{\ell}, t_{k}\right)$ with $t_{k}>0$. Hence, without equity concerns it can never be optimal to tax capital at source: $t_{k}=0 .^{7}$ The intuition for this standard result is that a small country faces a fixed rate of return on capital and, thereby, an infinitely elastic capital supply. Capital taxes would then be entirely shifted over to the immobile factor, which makes it less costly to tax this factor directly (Razin and Sadka, 1991; Bucovetsky and Wilson, 1991).

Disutility from unequal tax rates. First, consider the case where concerns for tax equity only affect utility levels $\left(\Omega_{k} \leq 0, \Omega_{\ell} \geq 0\right.$ with at least one strict inequality) but do not have any incentives effects (i.e., $\psi_{k}=\psi_{\ell} \equiv 0$ ). Then (20) continues to hold and we get from (18) and (19) that

$$
\frac{\partial W}{\partial t_{\ell}}=\frac{1}{k} \cdot \frac{\partial W}{\partial t_{k}}-\lambda \frac{t_{k} k^{\prime} L^{*}}{k}-\Omega_{\ell}+\frac{1}{k} \Omega_{k}
$$

This equation differs from (21) only by the term $-\Omega_{\ell}+\Omega_{k} / k<0$, implying that zero taxation of capital is no longer desirable: at $t_{k}=0$ and $\frac{\partial W}{\partial t_{\ell}}=0$, we get $\frac{\partial W}{\partial t_{k}}>0$ instead of $\frac{\partial W}{\partial t_{k}}=0$ such that a positive $t_{k}$ is warranted. Intuitively, with preferences for equal taxation, capital taxation not only has economics costs (distortion of the capital intensity), but also reduces the psychological costs from tax differences. For later use, note that

$$
L^{*} t_{k} k^{\prime} / k=\frac{1}{\lambda}\left(\frac{1}{k} \Omega_{k}-\Omega_{\ell}\right)
$$

must hold in a welfare maximum.

$\overline{{ }^{7} \text { Formally, if } \frac{\partial V}{\partial t_{\ell}}=0 \text {, one gets } \frac{\partial V}{\partial t_{k}}<0 \text { for all }} t_{k}>0$ such that a reduction of $t_{k}$ is worthwhile. 
Incentive effects. Suppose now that deviations from the tax equity norm do not cause a deterioration in utility per se, but distort the incentives to provide labour. I.e., we shall assume that $\psi_{k}\left(t_{\ell}, t_{k}\right) \leq 0 \leq \psi_{\ell}\left(t_{\ell}, t_{k}\right)$ with at least one strict inequality, while we reset $\Omega_{k}=\Omega_{\ell} \equiv 0$. Then the partial derivatives of equilibrium employment with respect to the tax rates are given by

$$
\frac{\partial L^{*}}{\partial t_{\ell}}=-\frac{1}{E_{\ell \ell}} \cdot\left(1+E_{\ell \psi} \cdot \psi_{\ell}\right) \quad \text { and } \quad \frac{\partial L^{*}}{\partial t_{k}}=-\frac{1}{E_{\ell \ell}} \cdot\left(k+E_{\ell \psi} \cdot \psi_{k}\right) .
$$

Using (24), it follows from (18) and (19) that

$$
\frac{\partial W}{\partial t_{\ell}}=\frac{1}{k} \cdot \frac{\partial W}{\partial t_{k}}-\lambda L^{*} \frac{t_{k} k^{\prime}}{k}+\underbrace{\left(\frac{1}{k} \psi_{k}-\psi_{\ell}\right)\left[E_{\psi}+\lambda\left(t_{\ell}+t_{k} k\right) \frac{E_{\ell \psi}}{E_{\ell \ell}}\right]}_{<0} .
$$

This again implies that no taxation of capital can never be optimal: For any $\left(t_{\ell}, t_{k}\right)=\left(t_{\ell}, 0\right)$, we get $\frac{\partial V}{\partial t_{k}}>k \cdot \frac{\partial V}{\partial t_{\ell}}$ such that an increase in $t_{k}$ is warranted. In an interior solution $\frac{\partial W}{\partial t_{k}}=\frac{\partial W}{\partial t_{\ell}}=0$ and, from (25),

$$
L^{*} \frac{t_{k} k^{\prime}}{k}=\frac{1}{\lambda}\left(\frac{1}{k} \psi_{k}-\psi_{\ell}\right)\left[E_{\psi}+\lambda\left(t_{\ell}+t_{k} k\right) \frac{E_{\ell \psi}}{E_{\ell \ell}}\right]
$$

To sum up:

Result 1 In the absence of tax equity concerns, capital should remain untaxed. In the presence of equity concerns, whether they shape incentives or just affect utility levels, a zero tax rate on capital is never optimal.

Result 1 shows that the standard recommendation that small open economies should leave capital untaxed balances on a knife's edge. Any effect providing capital taxation with some extra marginal benefit induces the government to rely on at least some capital taxation. Here, concerns for tax equity do the job.

\subsection{Comparative statics with level effects}

The inclusion of tax equity considerations provides governments with incentives to levy positive capital tax rates. But precisely how does the strength of equity concerns affect optimal tax policy? To answer this, we first consider the case where tax equity concerns do not impact on work incentives (i.e., $\psi$ is a constant). To be able to measure the intensity of equity concerns, we suppose that equity concerns are assuaged as soon as the difference between capital and labour tax rates narrows. Then $\Omega \Omega$ only depends on the gap between labour and capital tax rates:

$$
\Omega=\tilde{\Omega}\left(\beta \cdot\left(t_{\ell}-t_{k}\right)\right)
$$


with $\tilde{\Omega}^{\prime}>0$ and $\tilde{\Omega}^{\prime \prime} \geq 0$. Parameter $\beta>0$ then serves as a parametric measure for the strength of equity concerns. The comparative statics of $\left(t_{\ell}, t_{k}\right)$ with respect to $\beta$ are given through:

$$
\left(\begin{array}{ccc}
W_{\ell \ell} & W_{\ell k} & G_{\ell} \\
W_{\ell k} & W_{k k} & G_{k} \\
G_{\ell} & G_{k} & 0
\end{array}\right) \cdot\left(\begin{array}{c}
\mathrm{d} t_{\ell} \\
\mathrm{d} t_{k} \\
\mathrm{~d} \lambda
\end{array}\right)=\left(\begin{array}{c}
-W_{\ell \beta} \\
-W_{k \beta} \\
0
\end{array}\right) \mathrm{d} \beta
$$

with $W_{x y}=\partial^{2} W /\left(\partial t_{x} \partial t_{y}\right)$ and $W_{x \beta}=\partial^{2} W /\left(\partial t_{x} \partial \beta\right)$. From (18), (19), and (27) we get that

$$
W_{k \beta}=-W_{\ell \beta}=\Omega_{\ell \beta}:=\tilde{\Omega}^{\prime}+\beta\left(t_{\ell}-t_{k}\right) \cdot \tilde{\Omega}^{\prime \prime}>0
$$

for all $t_{\ell}>t_{k}$. Hence, applying Cramer's Rule to (28) we obtain:

$$
\begin{aligned}
\frac{\mathrm{d} t_{\ell}}{\mathrm{d} \beta} & =-\frac{1}{D} \cdot \Omega_{\ell \beta} \cdot\left(G_{k}^{2}+G_{\ell} G_{k}\right) \\
\frac{\mathrm{d} t_{k}}{\mathrm{~d} \beta} & =\frac{1}{D} \cdot \Omega_{\ell \beta} \cdot\left(G_{\ell}^{2}+G_{\ell} G_{k}\right) \\
\frac{\mathrm{d}\left(t_{\ell}-t_{k}\right)}{\mathrm{d} \beta} & =-\frac{1}{D} \cdot \Omega_{\ell \beta} \cdot\left(G_{k}+G_{\ell}\right)^{2} .
\end{aligned}
$$

Here,

$$
D=2 G_{k} G_{\ell} W_{\ell k}-\left(G_{k}^{2} W_{\ell \ell}+G_{\ell}^{2} W_{k k}\right)
$$

is the determinant of the bordered Hessian on the LHS of (28). In a welfare maximum, $D>0$ as well as $W_{k k}, W_{\ell \ell}<0$.

Observe from (28) that the weak assumption $\tilde{\Omega}^{\prime}>0$ (the individual feels worse the larger the tax rate differential) suffices to have equity concerns affect tax policies - we do not strictly need to assume that $\tilde{\Omega}^{\prime \prime} \geq 0$ (the psychological costs of tax inequity increase more than proportionately with the tax gap).

As can be seen immediately from (31), a stronger concern for tax equity has an unambiguous effect on the tax rate differential: $\left(t_{\ell}-t_{k}\right)$ is strictly decreasing in $\beta$, irrespective of the signs of the partial derivatives of the Laffer curve $\left(G_{\ell}, G_{k}\right)$. Starting from $t_{\ell}>t_{k}=0$ at $\beta=0$, the stronger the tax equity norm, the closer the tax structure moves towards equal tax rates:

$$
\frac{\mathrm{d}\left(t_{\ell}-t_{k}\right)}{\mathrm{d} \beta}<0 .
$$

To determine the signs of (29) and (30), we manipulate these expressions in the following way. From (20), (14), (15), (23) and $\Omega_{\ell}=-\Omega_{k}$, it follows that we have

$$
G_{\ell}=\frac{1}{k} G_{k}-\frac{1}{\lambda} \Omega_{k}\left(1+\frac{1}{k}\right)
$$

in an interior equilibrium. Observe from (18) that $G_{\ell}>0$ in an optimum. Substituting for $G_{\ell}$ from (32) into (29), we obtain 


$$
\frac{\mathrm{d} t_{\ell}}{\mathrm{d} \beta}=\underbrace{-\frac{1}{D} \cdot \Omega_{\ell \beta}}_{<0} \cdot G_{k}\left(1+\frac{1}{k}\right)\left[G_{k}-\frac{\Omega_{k}}{\lambda}\right] \gtreqless 0,
$$

where $\Omega_{k} / \lambda<0$. Thus, the effects from stronger tax equity concerns on the labour tax rate are unclear in sign. If $G_{k}>0$, the labour tax decreases with the strength of the equity concern. This accords with intuition: the more upset workers are with privileged capital taxation, the lower the tax burden they are willing to accept on their own incomes. However, the counter-intuitive case, that a stronger desire to correct for tax inequity is associated with higher labour taxation may also occur. This can happen if $G_{k}<0$, i.e. if the economy is on the downward-sloped part of the Laffer curve of the capital tax rate (given that $G_{\ell}$ and, from (32), $G_{k}-\frac{\Omega_{k}}{\lambda}$ are positive). In Example 1 below we will show that under certain conditions government in fact has an incentive to push the economy beyond the maximum of the (partial) Laffer-curve for the capital tax. Similar as for (33) one can show that

$$
\frac{\mathrm{d} t_{k}}{\mathrm{~d} \beta}=-\frac{1}{k} \frac{\mathrm{d} t_{\ell}}{\mathrm{d} \beta} \frac{1}{G_{k}}\left[\left(G_{k}-\frac{\Omega_{k}}{\lambda}\right)-\frac{k \Omega_{k}}{\lambda}\right] .
$$

This expression is positive, irrespective of the sign of $G_{k}$. Thus, we get a monotonic increase of the capital tax rate with the strength of equity concerns:

$$
\frac{\mathrm{d} t_{k}}{\mathrm{~d} \beta}>0
$$

The observation that the tax on labour may increase when tax equity concerns grow stronger deserves an explanation. An increase in $\beta$ calls for a higher $t_{k}$. If $t_{k}$ is high enough, this will ceteris paribus cause tax revenues to drop $\left(G_{k}<0\right)$, due to a reduction both in the capital stock and wages. As revenue shortfalls are not allowed with an exogenous budget requirement, the tax on labour consequently has to rise (but at a lower pace than the capital tax rate as $\left(t_{\ell}-t_{k}\right)$ is bound to decrease).

To see that $\frac{\mathrm{d} t_{\ell}}{\mathrm{d} \beta}$ might indeed be an optimal policy response, have a look at

Example 1. In this and the following examples, we consider a Cobb-Douglas technology where per-capita output is produced according to $y=k^{\alpha}$. We parameterize the disutility from labour by $E=0.5 \cdot \psi \cdot \ell^{2}$. The disutility from tax rate differentials is assumed to follow $\Omega=0.5 \cdot \beta \cdot\left(t_{\ell}-t_{k}\right)^{2}$. The parameter $\alpha$, capital's share of output, is set equal to 0.25 . The "dislove for work" parameter, $\psi$, is set to 0.1 , and the world market's rental rate, $r$, to 0.25 . Figure 1 depicts optima for different values of $\beta$.

Each graph plots tax indifference curves for $V\left(t_{\ell}, t_{k}\right)$ (dashed curves) and a government isobudget contour (solid lines) in $\left(t_{\ell}, t_{k}\right)$-space. The aspired revenue level and (since there are no incentive effects) the iso-budget contours for the government are the same in all panels. The 
(lower leg of the) iso-budget contour is negatively sloped for moderate capital tax rates: a higher capital tax entails higher tax revenues and, thus, allows for a lower tax rate on labour to meet the budget requirement. However, eventually the negative effect of a higher capital tax rate on tax revenues (a lower tax base induced by capital flight) dominates, such that the same level of $g$ can only be met at higher taxes on labour. The shape of the $V$-indifference curves varies across the four panels of Figure 1 with the strength $\beta$ of the tax equity concern. For zero or low values of $\beta$ indifference curves are negatively sloped since individuals place high emphasis on the adverse effects of capital taxation on consumption $\left(w^{\prime}<0\right)$. For $\beta=0$ both the labour and the capital tax rate are considered as "bads" - while $t_{\ell}$ adversely affects consumption via lower net wages, a higher $t_{k}$ depresses gross wages. Indifference curves closer to the origin represent higher utility levels. With increasing concerns for tax equity, indifference curves bend upwards. Closing the tax gap is increasingly considered as good, and losses in material consumption can be less easily compensated for by a lower tax burden on labour income. ${ }^{8}$

Geometrically the indifference curve at an optimal tax mix must be tangent to the (lower leg of the) iso-budget contour representing the exogenous revenue requirement $\bar{g}$. In the benchmark case $(\beta=0)$, this point of tangency is on the vertical axis where capital is tax exempt. Starting from such a position, the point of tangency moves along the budget contour towards the $45^{\circ}$ line. This initially entails a reduction of $t_{\ell}$ and an increase in $t_{k}$. However, with equity concerns strong enough, eventually the upward-sloped part of the iso-budget contour might be entered. The optimal tax mix then leads the economy on the downward-sloped part of the (partial) Laffer for the capital tax rate (where $\left.G_{k}<0\right)$. Thus, it is shown that $\left(\frac{\mathrm{d} t_{\ell}}{\mathrm{d} \beta}>0\right)$ is possible. ${ }^{9}$

Equity concerns call for narrowing the spread between labour and capital taxation. Indeed, if it is possible to finance the exogenous revenue requirement at equal tax rates (the iso-budget contour intersects with the diagonal), $t_{\ell}=t_{k}$ will eventually be implemented when equity concerns $\beta$ grow strong enough. Such tax rate equalization need not be feasible, in particular not when budget requirements are sufficiently high. An economy with strong tax equity motives will then (geometrically) remain at that situation on the iso-budget contour that lies at minimal distance to the diagonal. From here onwards, $\frac{\mathrm{d} t_{\ell}}{\mathrm{d} \beta}=\frac{\mathrm{d} t_{\ell}}{\mathrm{d} \beta}=0$.

We sum up the general findings of this section in

Result 2 Suppose that individual well-being decreases when the gap between the tax rates on capital and labour widens.

\section{A more intense concern for tax equity calls for a higher tax on capital and for a more}

\footnotetext{
${ }^{8}$ In the extreme, when tax equity concern becomes overwhelmingly strong, indifference curves would be linear with slope +1 and the highest utility level is represented by the $45^{\circ}$-line. All tax combinations along the $45^{\circ}$-line are then considered as equally good.

${ }^{9}$ Formally, the tax mix $\left(t_{k}, t_{\ell}\right)$ that is at minimum distance to the $45^{\circ}$-line satisfies, on the iso-budget contour for $g$, the condition $-G_{k} / G_{\ell}=1$. From (29) to (31), this implies that tax rates do no further vary with $\beta$.
} 

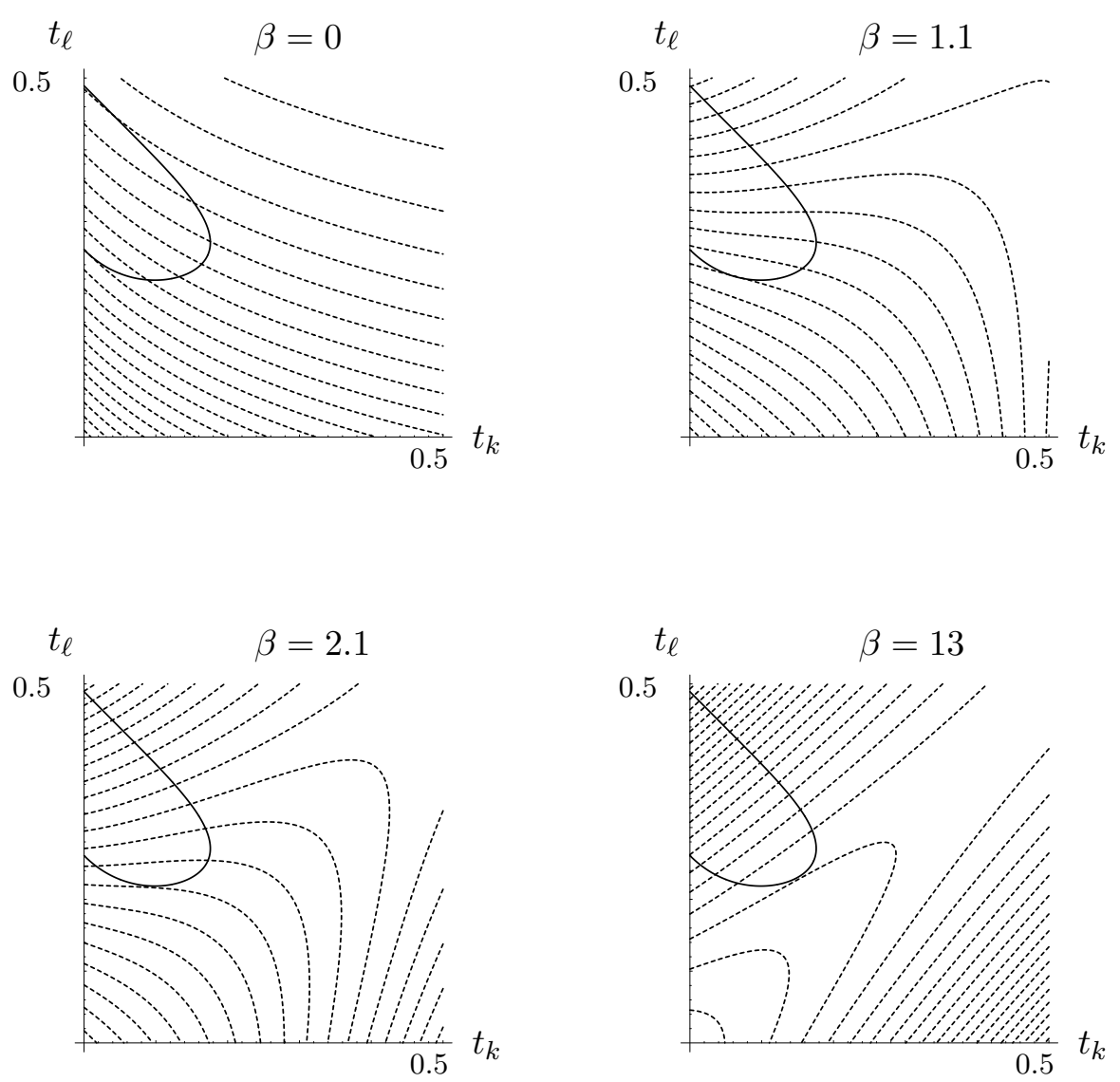

Figure 1: Tax equity without incentive effects. Government iso-budget contour (solid) and indifference curves (dashed) for varying values of $\beta$.

narrow gap between capital and labour tax rate.

2. Starting from weak levels, a strengthening of tax equity concerns calls for a lower tax on labour. However, if equity concerns become sufficiently strong, the optimal tax rate on labour may eventually increase. This occurs if and only if, at the optimal tax mix, the economy operates on the decreasing part of the Laffer curve for the capital tax. ${ }^{10}$

The significant (economic) inefficiency identified in the last effect in item b) is interesting in itself. Already Boskin and Sheshinski (1978) conjectured that the inclusion of social preferences (in their case: concerns about relative consumption) potentially removes the economic barriers for increasing tax rates to the point where disincentive effects actually reduce tax revenues.

\footnotetext{
${ }^{10}$ The economy will never operate on the downward-sloped part of its total Laffer curve ( $G_{\ell}, G_{k}$ both negative); $G_{\ell}$ must be positive from the FOC (18).
} 
Tax equity concerns provide a case in point here. In an alternative interpretation the equity norm may represent tax envy. Then the choice of economically questionable tax policies (i.e., operating in the decreasing part of the Laffer curve) is reminiscent of Elster's (1991, p. 66) warning that assuaging its envy may come at the expense of a society's substantial economic interests. $^{11}$

It is informative to study how the level of equilibrium labour supply $L^{*}\left(t_{\ell}, t_{k}\right)$ varies with the strength of tax equity concerns. From (12) in conjunction with (4) to (6), (34), and (33) we obtain: ${ }^{12}$

$$
\begin{aligned}
\frac{\mathrm{d} L^{*}}{\mathrm{~d} \beta} & =\frac{\partial L^{*}}{\partial t_{\ell}} \frac{\mathrm{d} t_{\ell}}{\mathrm{d} \beta}+\frac{\partial L^{*}}{\partial t_{k}} \frac{\mathrm{d} t_{k}}{\mathrm{~d} \beta}=-\frac{\partial \ell^{S}}{\partial w} \cdot\left(\frac{\mathrm{d} t_{\ell}}{\mathrm{d} \beta}+k \frac{\mathrm{d} t_{k}}{\mathrm{~d} \beta}\right) \\
& =-\frac{\partial \ell^{S}}{\partial w} \cdot \frac{\mathrm{d} t_{\ell}}{\mathrm{d} \beta} \cdot \frac{(1+k) \Omega_{k}}{\lambda G_{k}} \\
& =\underbrace{\frac{\partial \ell^{S}}{\partial w}}_{>0} \cdot \underbrace{\frac{1}{D} \cdot \Omega_{\ell \beta} \cdot \frac{(1+k)^{2}}{k}}_{>0} \cdot \underbrace{\left(G_{k}-\frac{\Omega_{k}}{\lambda}\right)}_{>0} \cdot \underbrace{\frac{\Omega_{k}}{\lambda}}_{<0}<0
\end{aligned}
$$

Hence,

Corollary 1 People in an economy with more intense concerns for tax equity work less.

This observation should be interpreted against the backdrop that the equity norm itself does not exert any incentive effects (in the present scenario). The impact of tax equity concerns on labour supply is entirely indirect, via the attending optimal tax structure.

\subsection{Comparative statics with incentive effects}

Now we turn to the effects of stronger fairness concerns when tax equity concerns impact on work incentives (i.e., $\psi_{\ell}>0>\psi_{k}$ but $\Omega_{\ell}=\Omega_{k} \equiv 0$ ). This change affects indifference maps for $V\left(t_{\ell}, t_{k}\right)$ as well as the iso-budget contour $G\left(t_{\ell}, t_{k}\right)=\bar{g}$ - which now changes its shape when equity concerns vary.

For low levels of equity concerns, the effects are similar as in the "level effect"-scenario of the previous section: starting from $t_{k}=0$, stronger equity concerns call for raising $t_{k}$ and lowering $t_{\ell}$. Eventually, higher equity concerns may call for an increase in the labour tax rate $t_{\ell}$. However, unlike in the previous scenario, this does neither imply nor necessitate that the economy is on the decreasing leg of its Laffer curve. We demonstrate this in

\footnotetext{
${ }^{11}$ Lévy-Garboua et al. (2009) experimentally show that workers who respond sensitively to violations of a tax equity norm refuse to work. This implies that higher tax rates (viz., more severe violations of the equity norm) lead to decreasing tax revenues. This undesirable Laffer curve effect has to be clearly distinguished from our observation where it may be optimal to bring the economy on the downward-sloped side of the (partial) Laffer curve.

${ }^{12}$ The positive sign of the bracketed expression is implied by $G_{\ell}>0$ in (32).
} 
Example 2. As above, preferences are parameterized by $u=c-0.5 \cdot \psi \cdot \ell^{2}$. But now $\psi$ is not a constant but a function given by

$$
\psi=\psi_{0}+0.5 \cdot \beta \cdot\left(t_{\ell}-t_{k}\right)^{2}
$$

The level of spending is again exogenously fixed. Throughout the numerical examples, we set $\psi_{0}$ equal to 0.1 and $\bar{g}=0.12$; all other parameters take on the same values as in Example $1 .^{13}$
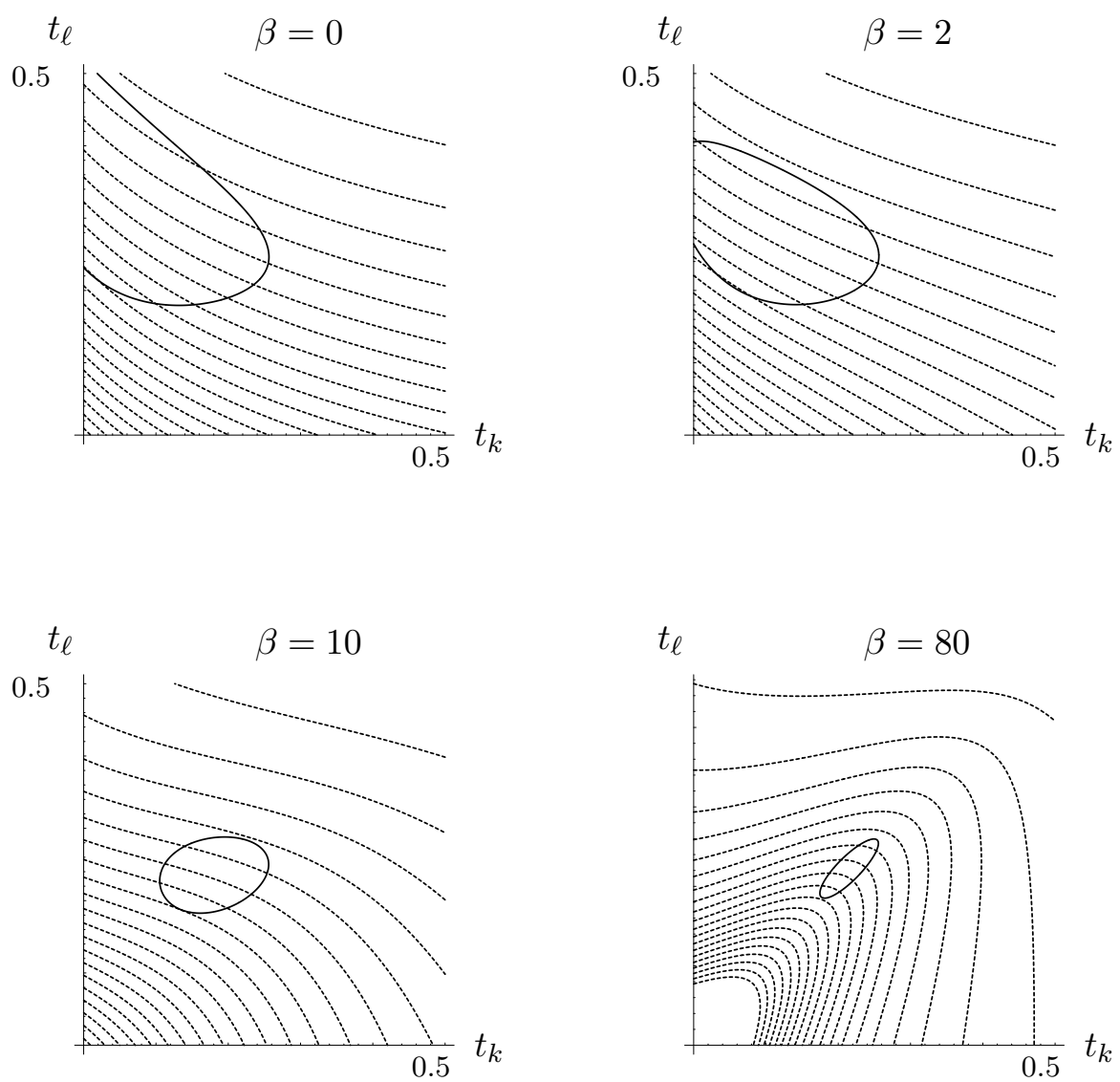

Figure 2: Tax equity with incentive effects. Government iso-budget contours (solid) and indifference curves (dashed) for varying values of $\beta$.

The four panels in Figure 2 depict the government iso-budget contour (solid line) and indifference curves (dashed lines) for different values of $\beta$. Unlike in Figure 1, the iso-budget contours vary with the strength of the equity norm. They move into the direction of the $45^{\circ}$-line in $\left(t_{\ell}, t_{k}\right)$ space and tend to bend upwards when $\beta$ increases. The reason is that (starting from a situation with $t_{\ell}>t_{k}$ ) a higher capital tax motivates people to work more. The same level of tax revenues ${ }^{13}$ For $\beta=0$, scenarios here and in Example 1 coincide. Cf. also the upper left panels in Figures 1 and 2. 
can be generated at a lower labour tax than in the absence of incentive effects. Moreover, when work disincentives from tax differentials are very large, tax revenues can only be earned when the zax rates are sufficiently close to each other. ${ }^{14}$ The effect of $\beta$ on the shape of indifference curves looks qualitatively similar as in Figure 1.

Figure 2 shows that the optimal capital tax rate decreases monotonically with $\beta$. Initially, the tax rate on labour falls. However, as the transition from the third to the fourth panel shows, the labour tax rate eventually may increase again. Observe that all optimal tax mixes lie on the lower and decreasing arc of the iso-budget contours. I.e., tax revenues are increasing in either tax rate.

Result 3 Suppose that a widening of the gap between labour and capital tax rates depress work incentives. Starting from weak levels, a stronger tax equity concern calls for a higher tax on capital and a lower tax on labour. However, if equity concerns become sufficiently intense, increasing the labour tax rate may eventually become optimal.

\section{Endogenous government expenditure}

We now analyze the effects of tax equity concerns when government spending is endogenous. Such an analysis appears worthwhile since tax equity norms make government activities less desirable per se: they call for tax mixes that are excessively costly from a pure efficiency perspective; obedience to tax equity norms increases the marginal costs of public funds. This might impact on the optimal level of government expenditures - and a first intuition would suggest that greater concerns for tax equity call for smaller governments. But we better have a closer look.

\subsection{Capital taxation and the size of government}

We recycle the set-up of Section 2. Again, the government chooses $t_{\ell}$ and $t_{k}$ in order to maximize social welfare (= indirect utility). Allowing $g$ to vary rather than being preset, the government objective function reads as

$$
V\left(t_{\ell}, t_{k}\right):=\left(w\left(r+t_{k}\right)-t_{\ell}\right) \cdot L^{*}\left(t_{\ell}, t_{k}\right)-E\left(L^{*}\left(t_{\ell}, t_{k}\right), \psi\left(t_{\ell}, t_{k}\right)\right)+h\left(G\left(t_{\ell}, t_{k}\right)\right)-\Omega\left(t_{\ell}, t_{k}\right)
$$

\footnotetext{
${ }^{14}$ In the extreme case when people only care for tax equity, $t_{\ell}=t_{k}$ must hold (for any given $t_{k}$ ); otherwise people would not supply any labour at all.
} 
where $L^{*}(\cdot)$ and $G(\cdot)$ are defined as in (12) and (13). Differentiating $V$, as defined in (36), with respect to tax rates $\left(t_{k}, t_{\ell}\right)$ and using the Envelope Theorem gives:

$$
\begin{aligned}
\frac{\partial V}{\partial t_{\ell}} & =L^{*} \cdot\left[h^{\prime}(G)-1\right]+h^{\prime}(G) \cdot\left(t_{\ell}+t_{k} k\right) \cdot \frac{\partial L^{*}}{\partial t_{\ell}}-E_{\psi} \cdot \psi_{\ell}-\Omega_{\ell} \\
\frac{\partial V}{\partial t_{k}} & =k L^{*} \cdot\left[h^{\prime}(G)-1\right]+h^{\prime}(G) \cdot\left(\left(t_{\ell}+t_{k} k\right) \cdot \frac{\partial L^{*}}{\partial t_{k}}+t_{k} k^{\prime} L^{*}\right)-E_{\psi} \cdot \psi_{k}-\Omega_{k} \\
& =k \cdot \frac{\partial V}{\partial t_{\ell}}+h^{\prime}(G) t_{k} k^{\prime} L^{*}+k \Omega_{\ell}-\Omega_{k} .
\end{aligned}
$$

These conditions give rise to

Result 4 1. In the absence of tax equity concerns, capital should optimally never be taxed.

2. In the presence of tax equity concerns, whether they shape incentives or just affect utility levels, a zero tax rate on capital is never optimal.

3. The level of the government-provided good is always ${ }^{15}$ inefficiently low.

The analytical results on the tax structure and their interpretation coincide with those in Section 3.1. Also the proof of items 1 and 2 is similar as for Result 1. Consequently, we omit it (the optimality of a zero tax rate on capital was also proven by Fuest and Huber, 2001).

The under-provision of the government good in the absence of tax equity concerns (i.e., when $\psi_{\ell}=\Omega_{\ell}=0$ ) can be seen from equating (37) to zero with $t_{k}=0$; we then get the Atkinson-Stern Rule:

$$
h^{\prime}(G)=\frac{1}{1+\frac{\partial \ell^{S}}{\partial w} \cdot \frac{t_{\ell}}{\ell^{S}}}>1 .
$$

Hence, the marginal willingness-to-pay for the government good exceeds the marginal rate of transformation (which is equal to one). The reason for the under-provision is the financing through a distortionary (labour) tax. When tax equity concerns only affect the level of wellbeing (i.e., $\Omega_{\ell}>0=\psi_{\ell}$ ), the costs of public funds further increase since government expenditures will now partly be financed through the even less efficient capital tax.

\subsection{Comparative statics with level effects}

As in the previous section, let us consider the case that the feeling of inequitable taxation has no incentives effects, i.e., $\psi_{k}=\psi_{\ell} \equiv 0$. Only the level effect of tax equity concerns is operative. For simplicity (and as in Section 3) let us assume that $\Omega$ is given by (27): $\Omega=\tilde{\Omega}\left(\beta \cdot\left(t_{\ell}-t_{k}\right)\right.$ ). Though comparative statics get quite messy, some reasonably general results are available. Our first

\footnotetext{
${ }^{15}$ There is one (immaterial) exception: With exogenous labour supply and in the absence of tax equity concerns, government expenditures are optimally at their efficient level. This can be seen in (37) when $\partial L^{*} / \partial t_{\ell}=\psi_{\ell}=$ $\Omega_{\ell} \equiv 0$.
} 
finding is in the spirit of Result 2; it holds irrespective of whether labour supply is endogenous or exogenous:

Result 5 Suppose that tax equity concerns are not too strong initially (i.e., $\beta$ is positive, but small).

1. A more intense concern for tax equity, represented by an increase $\beta$, calls for a decrease in the tax rate on labour, an increase in the tax rate on capital and, consequently, a decrease in the tax rate differential.

2. The optimal level of government expenditures decreases when concerns for tax equity get stronger.

The proof of this result is in Appendix 1. From the second item in Result 5, stronger concerns for tax equity call for cutting back the size of the public sector. The intuition appears straightforward: Capital taxation is economically more costly than labour taxation. When equity concerns induce the economy to rely more heavily on the less efficient tax instrument, the (economic) opportunity costs of the government good rise. Consequently, its optimal provision level decreases.

While Result 5 sounds plausible, a strong caveat has to be added: the qualification of only weak equity concerns made in the proposition is indeed essential. If concerns with tax equity are strong already, a further intensification may call for an increase in labour taxes and/or a rise in government expenditures. This is illustrated by means of

Example 3: As in Example 1, we choose $y=f(k)=k^{\alpha}$. To arrive at explicit solutions, we further suppose that labour supply is inelastic at some level $\bar{L}>0$. Utility is then measured by $u=c-\Omega$, where $\Omega=0.5 \beta\left(t_{\ell}-t_{k}\right)^{2}$.

Figure 3 illustrates optimal policies when parameter values are set to $\bar{L}=0.2, \alpha=1 / 3$, and $r=0.2$. The first graph shows that $\beta$ and $t_{k}$ are strictly positively related, as expected. The other three graphs plot, respectively, $\left(t_{\ell}-t_{k}\right), t_{\ell}$, and optimal government expenditure $G\left(t_{\ell}(\beta), t_{k}(\beta)\right)$ against $t_{k}$ - which translates, by the positive association between $\beta$ and $t_{k}$ from the first graph, into similarly shaped plots against $\beta$. As can be seen, $t_{k}$ and the tax rate differential $\left(t_{\ell}-t_{k}\right)$ move monotonically with $\beta$, but the labour tax rate initially falls and later rises when tax equity concerns intensify beyond some level. This eventual non-monotonicity of the labour tax rate in the strength of equity considerations may be explained as follows: With strong equity concerns, the tax rate on capital is quite high and government finance is economically quite costly. ${ }^{16}$ To reduce the economic costs of a further narrowing (demanded by even stronger equity concerns) in the tax gap may then call for a stronger reliance on the labour

${ }^{16}$ This effect is more severe the more elastically capital responds to higher taxation. 

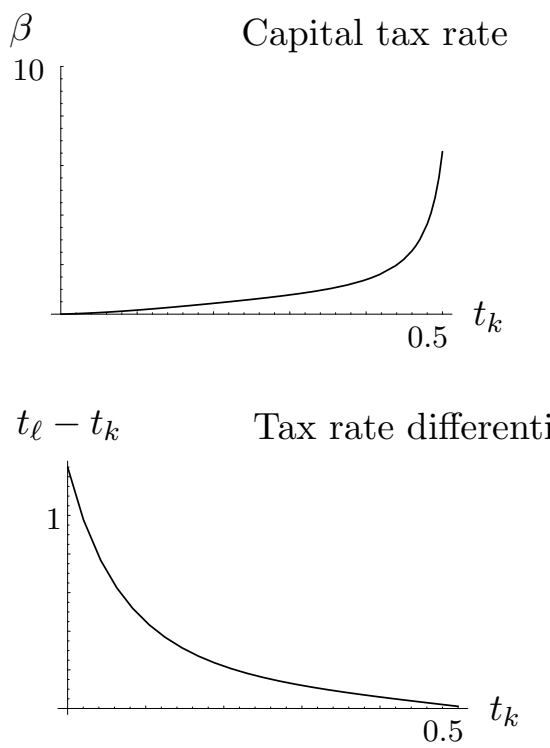
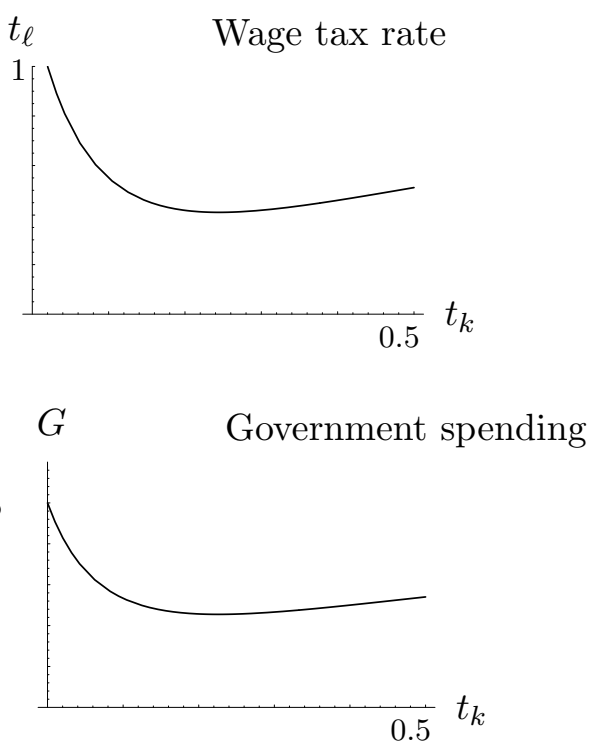

Figure 3: Optimal policies when government spending is endogenous.

tax, which is lump-sum here. Naturally, the increase in the labour tax must not offset the rise of the capital tax rate; the tax differential is bound to decrease.

The fourth graph in Figure 3 shows that also government expenditures are non-monotonic in $\beta$, first falling, then rising. The simultaneous increase in both tax rates just explained yields higher revenues for the government. Thus, the first-order intuition that an increase in the marginal costs of public funds (due to greater reliance on capital taxes, induced by larger equity concerns) always calls for smaller government is not correct. An equity-induced reduction in the tax spread may well go along with a larger government budget.

Result 6 In spite of a greater reliance of government finance on capital taxes, stronger tax equity concerns may call for an expansion of government expenditures.

Of course, Result 5 remains valid in that government expenditure is always inefficiently low in the presence of equity concerns, even though it may increase once equity concerns get stronger. ${ }^{17}$ The upper left panel in Figure 3 depicts a positive relationship between the strength of equity concerns and the optimal capital tax rate. Other than the effects shown in the remaining three panels, this relationship is indeed general in the case of exogenous labour supply, but not in the case of endogenous labour supply:

\footnotetext{
${ }^{17}$ In the example, an inelastic labour supply is assumed. Hence, the third item in Result 3 does not strictly apply (see previous footnote). Rather, in the example $G$ is at its efficient level for $\beta=0$ : we have $G=0.25$, which solves $1=h^{\prime}(G)=0.5 G^{-0.5}$.
} 
Result 7 1. For endogenous government spending and exogenous labour supply, a stronger concern with tax equity always calls for an increase in the capital tax rate.

2. For endogenous government spending but endogenous labour supply, a stronger concern with tax equity may call for a lower tax rate on capital. A necessary (but insufficient) condition for this to occur is that the labour supply function is strictly convex in the net wage (i.e., $\left.\partial^{2} \ell^{S} / \partial w^{2}>0\right){ }^{18}$

The proof is in Appendix 2. Result 7 shows that the a priori intuition that a higher degree of tax equity calls for higher taxes on capital is only true for exogenous labour supply. For variable labour supply, a stronger concern for tax equity may also be associated with lower taxes on capital income, given that the labour supply function is sufficiently convex in the net wage. The reason is the following: With relatively strong concerns for tax equity the capital tax rate will optimally be positive (see Result 4). Even stronger equity concerns call for further narrowing the spread between labour and capital taxes. One way to achieve this is to cut back both tax rates, but with a larger reduction in the labour tax rate. Such tax cuts will increase the gross wage (lowering $t_{k}$ boosts $k$ ), the net wage $\left(w-t_{\ell}\right.$ rises), indirect utility $V$, and finally labour supply (both via the standard wage effect and the reduced disincentive by the smaller tax gap). If these effects are strong enough (here the convexity requirement jumps in), such a move need not reduce, and may even increase, government expenditure, rendering the joint tax cut indeed feasible and optimal. Recall, however, the necessary requirements: strong equity concerns and a highly elastic labour supply.

With invariant labour supply, only the comparative statics for the capital tax rates are unambiguously characterized in Result 7. All other comparative statics depend on the sign and magnitude of $k^{\prime \prime}$, i.e., on the curvature of the capital demand function or, which is the same, on the third derivative of the production function $f(k)$. In addition, the case of an endogenous labour supply entails a complex interaction between equity and efficiency effects: Closing the spread between labour and capital tax rates increases labour supply via reduced disincentives for work. On the other hand, it also raises the excess burden of taxation, due to the mobility of capital. These opposing effects make it virtually impossible to arrive at any predictions of at least moderate generality when fairness concerns are strong and labour supply is exogenous. However, Example 3 shows that counter-intuitive effects may arise already when labour supply is fixed; by a continuity argument they cannot be excluded in case of an endogenous labour supply either.

\footnotetext{
${ }^{18}$ In our model, this convexity condition is equivalent to the marginal disutility from labour being concave: further implicit differentiation of $(3)$ gives $\partial^{2} \ell / \partial w^{2}=E_{\ell \ell \ell} /\left(-E_{\ell \ell}\right)^{3}$.
} 


\section{Conclusion}

In this paper, we augmented a standard model for factor taxation in small open economies by concerns about tax equity. Violating standard neoclassical assumptions, we endowed individuals with direct preferences over tax rates, allowing for a distinction between equity considerations that shape work incentives and such that just scale up or down utility levels. Optimal tax policies have to balance three policy goals: (i) maintaining a solid capital base in spite of international mobility, (ii) generating sufficiently high tax revenue, and (iii) avoiding large imbalances between capital and labour taxation.

The third requirement upsets the standard recommendation of exempting capital from taxation. Moreover, our comparative statics reveal some unexpected non-monotonicities: With weak concerns about tax equity the tax on capital should be higher and the tax on labour and (endogenous) government expenditures should be lower, relative to an economy that is unconcerned with tax equity. However, with intense concerns for tax equity these intuitive patterns turn out to be unstable: capital taxes might decrease, labour taxes increase, and government expenditure go up.

The potential implications of concerns for tax equity on the optimal structure of factor income taxation can be substantial. Moreover, they vary considerably with the strength of equity motives. Yet, while from the arguments provided in the introduction (justice principles, fairness considerations, relative deprivation, envy, etc.) the prevalence of such equity concerns appears highly plausible, we can at present not provide any measurable evidence for their intensity. We hope that by demonstrating the potential policy relevance of equity concerns, we shall encourage empirical work on the subject. 


\section{References}

Adams, J. S. (1963). Toward an Understanding of Inequity. Journal of Abnormal and Social Psychology 67, 422-436.

Alonso-Carrera J., J. Caballé, and X. Raurich (2006). Welfare Implications of the Interaction Between Habits and Consumption Externalities. International Economic Review 47, 557-571.

Alvarez-Cuadrado, F. (2007). Envy, Leisure and Restrictions on Working Hours. Canadian Journal of Economics 40, 1286-1310.

Barker, W.B. (2006). The Three Faces of Equality: Constitutional Requirements in Taxation. Case Western Reserve Law Review 57, 1-54.

Boadway, R., N. Marceau, and S. Mongrain (2007). Redistributive Taxation under Ethical Behaviour. Scandinavian Journal of Economics 103, 505-529.

Bordignon, M. (1993). A Fairness Approach to Income Tax Evasion. Journal of Public Economics $52,345-362$.

Boskin, M.J., and E. Sheshinski (1978). Optimal Redistributive Taxation When Individual Welfare Depends Upon Relative Income. Quarterly Journal of Economics 92, 589-601.

Brooks, C., and J. Manza (2006). Why Do Welfare States Persist? Journal of Politics 68, 816827.

Bucovetsky, S., and J.D. Wilson (1991). Tax competition with Two Tax Instruments. Regional Science and Urban Economics 21, 333-350.

Clark, A.E., and A.J. Oswald (1996). Satisfaction and Comparison Income. Journal of Public Economics 61, 359-381.

Cornelissen, T., Himmler, O. and T. Koenig (2010). Fairness Spillovers: The Case of Taxation. Mimeo.

Elster, J. (1991). Envy in Social Life, in R.J. Zeckhauser, ed., Strategy and Choice. MIT Press, Cambridge. Pp. 49-82. 
Fehr, E. and K. M. Schmidt (2006). The Economics of Fairness, Reciprocity and Altruism: Experimental Evidence, in S. Kolm and J. M. Ythier, eds. Handbook of the Economics of Giving, Altruism and Reciprocity, Vol. 1. North Holland, New York. Pp. 615-694.

Gordon, R. (1986). Taxation of Investment and Savings in a World Economy. American Economic Review 76, 1086-1102.

Haufler, A. (1997). Factor Taxation, Income Distribution and Capital Market Integration. Scandinavian Journal of Economics 99, 425-446.

Haufler, A., A. Klemm, and G. Schjelderup (2008). Economic Integration and the Relationship Between Profit and Wage Taxes. Public Choice 138, 423-446.

Kaplow, L. (1995). A Fundamental Objection to Tax Equity Norms: A Call for Utilitarianism. National Tax Journal 48, 497-514.

Kim, Y. (2007). Optimal Taxation and Political Equilibrium with Fairness Considerations. The Manchester School 75, 767-788.

Layard, R. (2006). Happiness and Public Policy: A Challenge to the Profession. Economic Journal 116, 24-33.

Lévy-Garboua, L., D. Masclet, and C. Montmarquette (2009). A Behavioral Laffer Curve: Emergence of a Social Norm of Fairness in a Real Effort Experiment. Journal of Economic Psychology 30), 147-161.

Luttmer, E. F. P. (2005). Neighbors as Negatives: Relative Earnings and Well-Being. Quarterly Journal of Economics 120, 963-1002.

Musgrave, R.A. (1959). The Theory of Public Finance, McGraw-Hill: New-York.

Neill, J. R. (2000). The Benefit and Sacrifice Principles of Taxation: A Synthesis. Social Choice and Welfare 17, 117-124.

Podder, N. (1996). Relative Deprivation, Envy and Economic Inequality. Kyklos 49, 353-376. 
Razin, A. and E. Sadka (1991). International Tax Competition and Gains from Tax Harmonization. Economics Letters 37, 69-76.

Runciman, W.G. (1966). Relative Deprivation and Social Justice. A Study of Attitudes to Social Inequality in Twentieth-Century England. University of California Press: Berkeley and Los Angeles.

Snyder, J., and G. Kramer (1988). Fairness, Self-Interest, and the Politics of the Progressive Income Tax. Journal of Public Economics 36, 197-230.

Sørensen, P.B. (1994). From the Global Income Tax to the Dual Income Tax: Recent Tax Reforms in the Nordic Countries. International Tax and Public Finance 1, 57-79.

Taylor, N. (2003). Understanding Taxpayers' Attitudes through Understanding Taxpayers' Identities, in V. Braithwaite, ed., Taxing Democracy. Aldershot, Ashgate. Pp. 71-92.

\section{Appendix 1: Proof of Result 5}

\section{Tax rates (item 1)}

From (27), $\Omega_{\ell \beta}=-\Omega_{k \beta}=\tilde{\Omega}^{\prime}+\beta\left(t_{\ell}-t_{k}\right) \tilde{\Omega}^{\prime \prime}>0$. Using (37) and (38), the comparative statics of $\left(t_{\ell}, t_{k}\right)$ with respect to $\beta$ are given by:

$$
\begin{aligned}
\left(\begin{array}{cc}
V_{\ell \ell} & V_{\ell k} \\
V_{\ell k} & V_{k k}
\end{array}\right) \cdot\left(\begin{array}{c}
\mathrm{d} t_{\ell} \\
\mathrm{d} t_{k}
\end{array}\right) & =-\left(\begin{array}{c}
V_{\ell \beta} \\
V_{k \beta}
\end{array}\right) \mathrm{d} \beta \\
& =\left[\tilde{\Omega}^{\prime}+\beta \cdot\left(t_{\ell}-t_{k}\right) \cdot \tilde{\Omega}^{\prime \prime}\right] \cdot\left(\begin{array}{c}
+1 \\
-1
\end{array}\right) \mathrm{d} \beta
\end{aligned}
$$

(with $V_{x y}=\partial^{2} V /\left(\partial t_{x} \partial t_{y}\right)$ and $V_{x \beta}=\partial^{2} V /\left(\partial t_{x} \partial \beta\right)$ ). Consequently, by Cramer's Rule:

$$
\begin{aligned}
\frac{\mathrm{d} t_{\ell}}{\mathrm{d} \beta} & =\frac{1}{D} \cdot\left[\tilde{\Omega}^{\prime}+\beta \cdot\left(t_{\ell}-t_{k}\right) \cdot \tilde{\Omega}^{\prime \prime}\right] \cdot\left(V_{k k}+V_{\ell k}\right) \\
\frac{\mathrm{d} t_{k}}{\mathrm{~d} \beta} & =-\frac{1}{D} \cdot\left[\tilde{\Omega}^{\prime}+\beta \cdot\left(t_{\ell}-t_{k}\right) \cdot \tilde{\Omega}^{\prime \prime}\right] \cdot\left(V_{\ell \ell}+V_{\ell k}\right) \\
\frac{\mathrm{d}\left(t_{\ell}-t_{k}\right)}{\mathrm{d} \beta} & =\frac{1}{D} \cdot\left[\tilde{\Omega}^{\prime}+\beta \cdot\left(t_{\ell}-t_{k}\right) \cdot \tilde{\Omega}^{\prime \prime}\right] \cdot\left(V_{\ell \ell}+V_{k k}+2 V_{\ell k}\right) .
\end{aligned}
$$

Here,

$$
D:=V_{\ell \ell} V_{k k}-V_{\ell k}^{2}
$$


is the determinant of the matrix on the LHS of (28). In a welfare maximum, $D>0$ as well as $V_{k k}, V_{\ell \ell}<0$. From (27), $\Omega_{\ell \ell}=\Omega_{k k}=-\Omega_{\ell k}=\beta^{2} \tilde{\Omega}^{\prime \prime}>0$. The claims in item 1 of Result 5 are, thus, proven if (but not only if) $V_{\ell k}<0 .{ }^{19}$

As an intermediate result (which will also be helpful in the proof of item 2) we report:

$$
\begin{aligned}
V_{\ell k} & =k V_{\ell \ell}+A_{1} \\
V_{k k} & =k V_{\ell k}+A_{2}
\end{aligned}
$$

where we set

$$
\begin{aligned}
A_{1}:= & h^{\prime \prime}(G) \frac{\partial G}{\partial t_{\ell}} L t_{k} k^{\prime}-h^{\prime}(G) t_{k} k^{\prime} \frac{\partial \ell}{\partial w}+(k+1) \beta^{2} \tilde{\Omega}^{\prime \prime} \geq 0 \\
A_{2}:= & h^{\prime \prime}(G) L t_{k} k^{\prime} \frac{\partial G}{\partial t_{k}}-h^{\prime}(G) k t_{k} k^{\prime} \frac{\partial \ell}{\partial w}+h^{\prime}(G) L\left(2 k^{\prime}+t_{k} k^{\prime \prime}\right) \\
& -(k+1) \beta^{2} \tilde{\Omega}^{\prime \prime}-h^{\prime} k^{\prime} \frac{\partial \ell}{\partial w}\left(t_{\ell}+t_{k} k\right)-k^{\prime} L .
\end{aligned}
$$

Equations (44) and (45) are proven below.

From Result 3 we get that $t_{k}=0$ for $\beta=0$. Hence, $A_{1}=0$ in this case. However, then $V_{\ell k}<0$ follows from (44). Hence, at $\beta=0$, we get from (40 to (42) that $\frac{\mathrm{d} t_{\ell}}{\mathrm{d} \beta}<0, \frac{\mathrm{d} t_{k}}{\mathrm{~d} \beta}>0$, and $\frac{\mathrm{d}\left(t_{\ell}-t_{k}\right)}{\mathrm{d} \beta}<0$. By continuity, the same holds for small positive values of $\beta$ (and, thus, $t_{k}$ ).

\section{Government expenditures (item 2)}

Observe that

$$
\frac{\mathrm{d} G}{\mathrm{~d} \beta}=G_{k} \cdot \frac{\mathrm{d} t_{k}}{\mathrm{~d} \beta}+G_{\ell} \cdot \frac{\mathrm{d} t_{\ell}}{\mathrm{d} \beta} .
$$

Suppose now that $\beta=0$ and, thus, $t_{k}=0$ (from Result 3). Then, using (15) and (14), we obtain

$$
\begin{aligned}
\frac{\mathrm{d} G}{\mathrm{~d} \beta} & =\left(\frac{\partial L}{\partial t_{k}} t_{\ell}+L^{*} k\right) \cdot \frac{\mathrm{d} t_{k}}{\mathrm{~d} \beta}+\left(\frac{\partial L}{\partial t_{\ell}} t_{\ell}+L^{*}\right) \cdot \frac{\mathrm{d} t_{\ell}}{\mathrm{d} \beta} \\
& =\left[\frac{\partial L}{\partial t_{\ell}} t_{\ell}+L^{*}\right] \cdot\left(k \frac{\mathrm{d} t_{k}}{\mathrm{~d} \beta}+\frac{\mathrm{d} t_{\ell}}{\mathrm{d} \beta}\right) \\
& =G_{\ell} \cdot\left(k \frac{\mathrm{d} t_{k}}{\mathrm{~d} \beta}+\frac{\mathrm{d} t_{\ell}}{\mathrm{d} \beta}\right) .
\end{aligned}
$$

Recall that $G_{\ell}>0$ in an optimum. ${ }^{20}$ Hence, $\frac{\mathrm{d} G}{\mathrm{~d} \beta}<0$ if and only if $k \frac{\mathrm{d} t_{k}}{\mathrm{~d} \beta}+\frac{\mathrm{d} t_{\ell}}{\mathrm{d} \beta}<0$. Verify that, using (44) and (45) and the fact that $A_{1}=0$ for $\beta=0$,

$$
\begin{aligned}
k \frac{\mathrm{d} t_{k}}{\mathrm{~d} \beta}+\frac{\mathrm{d} t_{\ell}}{\mathrm{d} \beta} & =\frac{1}{D} \cdot\left[\tilde{\Omega}^{\prime}+\beta \cdot\left(t_{\ell}-t_{k}\right) \cdot \tilde{\Omega}^{\prime \prime}\right] \cdot\left(-k V_{\ell \ell}-k V_{\ell k}+V_{k k}+V_{\ell k}\right) \\
& =\frac{1}{D} \cdot\left[\tilde{\Omega}^{\prime}+\beta \cdot\left(t_{\ell}-t_{k}\right) \cdot \tilde{\Omega}^{\prime \prime}\right] \cdot\left(-k^{2} V_{\ell \ell}+k\left(k V_{\ell \ell}+A_{1}\right)+A_{2}\right) \\
& =\frac{A_{2}}{D} \cdot\left[\tilde{\Omega}^{\prime}+\beta \cdot\left(t_{\ell}-t_{k}\right) \cdot \tilde{\Omega}^{\prime \prime}\right] .
\end{aligned}
$$

\footnotetext{
${ }^{19}$ In fact, this condition is overly strict. It would suffice that $V_{\ell k}<\max \left\{-V_{\ell \ell},-V_{k k}\right\}$.

${ }^{20}$ See (37) and (38): Conditions $V_{\ell}=V_{k}=0$ require that $G_{\ell}>0$ and $G_{k}-\frac{1}{h^{\prime}} \Omega_{k}>0$, respectively.
} 
In (48) both the square-bracketed expression and $D$ are positive. Moreover, using the definition of $D$ in (43) and, again, (44) and (45) and the fact that $A_{1}=0$ at $\beta=0$,

$$
D=V_{\ell \ell}\left(A_{2}-k A_{1}\right)-A_{1}^{2}=V_{\ell \ell} A_{2} .
$$

As $V_{\ell \ell}<0$ in an optimum, $D$ being positive necessitates $A_{2}<0$. In turn, we get that (48) is negative and, thus, $\frac{\mathrm{d} G}{\mathrm{~d} \beta}<0$ at $\beta=0$. Again, by continuity, this also holds for $\beta>0$, but small.

\section{Proof of (44) and (45)}

Calculate:

$$
\begin{aligned}
V_{\ell \ell} & =-\frac{\partial L}{\partial t_{\ell}}+h^{\prime \prime}(G)\left(\frac{\partial G}{\partial t_{\ell}}\right)^{2}+h^{\prime}(G) \frac{\partial^{2} G}{\partial t_{\ell}^{2}}-\Omega_{\ell \ell} \\
& =\frac{\partial \ell}{\partial w}+h^{\prime \prime}(G)\left(L-\left(t_{\ell}+t_{k} k\right) \frac{\partial \ell}{\partial w}\right)^{2}+h^{\prime}(G)\left(2 \frac{\partial L}{\partial t_{\ell}}+\left(t_{\ell}+t_{k} k\right) \frac{\partial^{2} L}{\partial t_{\ell}^{2}}\right)-\Omega_{\ell \ell} \\
& =\frac{\partial \ell}{\partial w}+h^{\prime \prime}(G)\left(L-\left(t_{\ell}+t_{k} k\right) \frac{\partial \ell}{\partial w}\right)^{2}+h^{\prime}(G)\left(-2 \frac{\partial \ell}{\partial w}+\left(t_{\ell}+t_{k} k\right) \frac{\partial^{2} \ell}{\partial w^{2}}\right)-\beta^{2} \tilde{\Omega}^{\prime \prime} .
\end{aligned}
$$

Moreover,

$$
\begin{aligned}
V_{\ell k}= & -\frac{\partial L}{\partial t_{k}}+h^{\prime \prime}(G) \frac{\partial G}{\partial t_{\ell}} \frac{\partial G}{\partial t_{k}}+h^{\prime}(G) \frac{\partial^{2} G}{\partial t_{\ell} \partial t_{k}}-\Omega_{\ell k} \\
= & k \frac{\partial \ell}{\partial w}+h^{\prime \prime}(G)\left(L-\left(t_{\ell}+t_{k} k\right) \frac{\partial \ell}{\partial w}\right)\left(L\left(k+t_{k} k^{\prime}\right)+\left(t_{\ell}+t_{k} k\right) \frac{\partial L}{\partial t_{k}}\right) \\
& +h^{\prime}(G)\left(\frac{\partial L}{\partial t_{k}}+\left(k+t_{k} k^{\prime}\right) \frac{\partial L}{\partial t_{\ell}}+\left(t_{\ell}+t_{k} k\right) \frac{\partial^{2} L}{\partial t_{\ell} \partial t_{k}}\right)-\Omega_{\ell k} \\
= & k \frac{\partial \ell}{\partial w}+h^{\prime \prime}(G)\left(L-\left(t_{\ell}+t_{k} k\right) \frac{\partial \ell}{\partial w}\right)\left(k\left[L-\left(t_{\ell}+t_{k} k\right) \frac{\partial \ell}{\partial w}\right]+L t_{k} k^{\prime}\right) \\
& +h^{\prime}(G)\left(-2 k \frac{\partial \ell}{\partial w}-t_{k} k^{\prime} \frac{\partial \ell}{\partial w}+k\left(t_{\ell}+t_{k} k\right) \frac{\partial^{2} \ell}{\partial w^{2}}\right)-\Omega_{\ell k} \\
= & k V_{\ell \ell}+A_{1} .
\end{aligned}
$$


With $A_{1}$ as defined in (46), this is (44). Finally,

$$
\begin{aligned}
V_{k k}= & w^{\prime} \frac{\partial L}{\partial t_{k}}+L w^{\prime \prime}+h^{\prime \prime}(G)\left(\frac{\partial G}{\partial t_{k}}\right)^{2}+h^{\prime}(G) \frac{\partial^{2} G}{\partial t_{k}^{2}}-\Omega_{k k} \\
= & k^{2} \frac{\partial \ell}{\partial w}-L k^{\prime}+h^{\prime \prime}(G)\left(k\left[L-\left(t_{\ell}+t_{k} k\right) \frac{\partial \ell}{\partial w}\right]+L t_{k} k^{\prime}\right)^{2} \\
& +h^{\prime}(G)\left(2\left(k+t_{k} k^{\prime}\right) \frac{\partial L}{\partial t_{k}}+\left(t_{\ell}+t_{k} k\right) \frac{\partial^{2} L}{\partial t_{k}^{2}}+\left(2 k^{\prime}+t_{k} k^{\prime \prime}\right) L\right)-\Omega_{k k} \\
= & k^{2} \frac{\partial \ell}{\partial w}-L k^{\prime}+h^{\prime \prime}(G)\left(k\left[L-\left(t_{\ell}+t_{k} k\right) \frac{\partial \ell}{\partial w}\right]+L t_{k} k^{\prime}\right)^{2} \\
& +h^{\prime}(G)\left(-2 k^{2} \frac{\partial \ell}{\partial w}-k t_{k} k^{\prime} \frac{\partial \ell}{\partial w}+k^{2}\left(t_{\ell}+t_{k} k\right) \frac{\partial^{2} \ell}{\partial w^{2}}+\left(2 k^{\prime}+t_{k} k^{\prime \prime}\right) L-k t_{k} k^{\prime} \frac{\partial \ell}{\partial w}-k^{\prime} \frac{\partial \ell}{\partial w}\left(t_{\ell}+t_{k} k\right)\right) \\
& -\Omega_{k k} \\
= & k^{2} \frac{\partial \ell}{\partial w}-L k^{\prime}+h^{\prime \prime}(G)\left\{k\left(L-\left(t_{\ell}+t_{k} k\right) \frac{\partial \ell}{\partial w}\right)\left(k\left[L-\left(t_{\ell}+t_{k} k\right) \frac{\partial \ell}{\partial w}\right]+L t_{k} k^{\prime}\right)\right. \\
& \left.+L t_{k} k^{\prime}\left(L t_{k} k^{\prime}+k\left(L-\left(t_{\ell}+t_{k} k\right) \frac{\partial \ell}{\partial w}\right)\right)\right\} \\
& +h^{\prime}(G)\left(-2 k^{2} \frac{\partial \ell}{\partial w}-k t_{k} k^{\prime} \frac{\partial \ell}{\partial w}+k^{2}\left(t_{\ell}+t_{k} k\right) \frac{\partial^{2} \ell}{\partial w^{2}}+\left(2 k^{\prime}+t_{k} k^{\prime \prime}\right) L-k t_{k} k^{\prime} \frac{\partial \ell}{\partial w}-k^{\prime} \frac{\partial \ell}{\partial w}\left(t_{\ell}+t_{k} k\right)\right) \\
& -\Omega_{k k} \\
= & k V_{\ell k}+A_{2} .
\end{aligned}
$$

With $A_{2}$ as defined in (47), this coincides with (45).

\section{Appendix 2: Proof of Result 7}

\section{Exogenous labour supply (item 1)}

From (41), $\mathrm{d} t_{k} / \mathrm{d} \beta$ is opposite in sign to $V_{\ell \ell}+V_{\ell k}$. Using (44), we get that $V_{\ell \ell}+V_{\ell k}=(1+k) V_{\ell \ell}+$ $A_{1}$. With exogenous labour supply, (46) gives $A_{1}=h^{\prime \prime}(G) L^{2} t_{k} k^{\prime}+(k+1) \beta^{2} \tilde{\Omega}^{\prime \prime}$. Moreover, from (49), $V_{\ell \ell}=h^{\prime \prime}(G) L^{2}-\beta^{2} \tilde{\Omega}^{\prime \prime}$ when labour supply is exogenous. Hence,

$$
V_{\ell \ell}+V_{\ell k}=h^{\prime \prime}(G) L^{2}\left(1+k+t_{k} k^{\prime}\right)=h^{\prime \prime}(G) L\left(G_{\ell}+G_{k}\right)<0,
$$

where we used (15) and (14) and exploited that from (32), it follows that

$$
G_{\ell}+G_{k}=\left(1+\frac{1}{k}\right)\left(G_{k}-\frac{1}{h^{\prime}} \Omega_{k}\right)
$$

must be positive in an inner solution. ${ }^{21}$ Thus, $\mathrm{d} t_{k} / \mathrm{d} \beta>0$.

\footnotetext{
${ }^{21}$ See also footnote 20. Note that in (32) we have to substitute for $\lambda$ with $h^{\prime}$ to obtain the analogue for endogenous government spending.
} 


\section{Endogenous labour supply (item 2)}

From (41) and 44, $\operatorname{sign}\left[\mathrm{d} t_{k} / \mathrm{d} \beta\right]=-\operatorname{sign}\left[(1+k) V_{\ell \ell}+A_{1}\right]$. With endogenous labour supply, (49) and (46) give

$$
\begin{aligned}
& (1+k) V_{\ell \ell}+A_{1} \\
& =\underbrace{\frac{\partial \ell}{\partial w}(1+k)\left(1 h^{\prime}\right)}_{<0}+\underbrace{h^{\prime \prime} G_{\ell}\left(G_{\ell}+G_{k}\right)}_{<0}+\underbrace{h^{\prime}\left(-\frac{\partial \ell}{\partial w}\right)\left(1+k+t_{k} k^{\prime}\right)}_{<0}+h^{\prime}\left(t_{\ell}+t_{k} k\right) \frac{\partial^{2} \ell}{\partial w^{2}}(1+k) .
\end{aligned}
$$

Here we used that $\Omega_{k k}=-\Omega_{\ell \ell}$. The first and second term on the RHS of (51) are negative since $h^{\prime}>1, G_{\ell}>0$ and $G_{\ell}+G_{k}>0$ must hold in an inner optimum. The sign of the third term in (51) can be determined from (15), (14) and (50) which yield that $L\left(1+k+t_{k} k^{\prime}\right)=$ $G_{\ell}+G_{k}+\frac{\partial \ell}{\partial w}\left(t_{\ell}+t_{k} k\right)(1+k)>0$. Thus, $\partial^{2} \ell / \partial w^{2}<0$ is sufficient for (51) to be negative and, thus, for $\mathrm{d} t_{k} / \mathrm{d} \beta>0$. 


\section{CESifo Working Paper Series}

for full list see www.cesifo-group.org/wp

(address: Poschingerstr. 5, 81679 Munich, Germany, office@cesifo.de)

3144 Philip E. Graves, Benefit-Cost Analysis of Environmental Projects: A Plethora of Systematic Biases, August 2010

3145 Sabrina Di Addario and Daniela Vuri, Entrepreneurship and Market Size. The Case of Young College Graduates in Italy, August 2010

3146 Shoshana Amyra Grossbard and Alfredo Marvăo Pereira, Will Women Save more than Men? A Theoretical Model of Savings and Marriage, August 2010

3147 Jarko Fidrmuc, Time-Varying Exchange Rate Basket in China from 2005 to 2009, August 2010

3148 Ilja Neustadt and Peter Zweifel, Is the Welfare State Sustainable? Experimental Evidence on Citizens' Preferences for Redistribution, August 2010

3149 Marcus Dittrich and Andreas Knabe, Wage and Employment Effects of Non-Binding Minimum Wages, August 2010

3150 Shutao Cao, Enchuan Shao and Pedro Silos, Fixed-Term and Permanent Employment Contracts: Theory and Evidence, August 2010

3151 Ludger Woessmann, Cross-Country Evidence on Teacher Performance Pay, August 2010

3152 Lorenzo C. G. Pozzi, Casper G. de Vries and Jorn Zenhorst, World Equity Premium Based Risk Aversion Estimates, August 2010

3153 Volker Grossmann, Thomas M. Steger and Timo Trimborn, Dynamically Optimal R\&D Subsidization, August 2010

3154 Alexander Haupt, Tim Krieger and Thomas Lange, A Note on Brain Gain and Brain Drain: Permanent Migration and Education Policy, August 2010

3155 António Afonso and Christophe Rault, Long-run Determinants of Sovereign Yields, August 2010

3156 Franziska Tausch, Jan Potters and Arno Riedl, Preferences for Redistribution and Pensions. What can we Learn from Experiments?, August 2010

3157 Martin Kolmar and Andreas Wagener, Inefficient Group Organization as Optimal Adaption to Dominant Environments, August 2010

3158 Kai Carstensen, Klaus Wohlrabe and Christina Ziegler, Predictive Ability of Business Cycle Indicators under Test: A Case Study for the Euro Area Industrial Production, August 2010 
3159 Horst Rottmann and Timo Wollmershäuser, A Micro Data Approach to the Identification of Credit Crunches, August 2010

3160 Philip E. Graves, Appropriate Fiscal Policy over the Business Cycle: Proper Stimulus Policies Can Work, August 2010

3161 Michael Binder and Marcel Bluhm, On the Conditional Effects of IMF Program Participation on Output Growth, August 2010

3162 Michael Binder, Qianying Chen, and Xuan Zhang, On the Effects of Monetary Policy Shocks on Exchange Rates, August 2010

3163 Felix J. Bierbrauer, On the Optimality of Optimal Income Taxation, August 2010

3164 Nikolaus Wolf, Europe's Great Depression - Coordination Failure after the First World War, September 2010

3165 Dan Kovenock and Brian Roberson, Conflicts with Multiple Battlefields, September 2010

3166 Jean-Pierre Ponssard and Catherine Thomas, Capacity Investment under Demand Uncertainty. An Empirical Study of the US Cement Industry, 1994-2006, September 2010

3167 Jørgen Juel Andersen, Jon H. Fiva and Gisle James Natvik, Voting when the Stakes are High, September 2010

3168 Michael Hoel, Is there a Green Paradox?, September 2010

3169 Scott Alan Carson, Nineteenth Century US African-American and White Female Statures: Insight from US Prison Records, September 2010

3170 Gil S. Epstein, Yosef Mealem and Shmuel Nitzan, Political Culture and Discrimination in Contests, September 2010

3171 Sara Fisher Ellison, Jeffrey Greenbaum and Wallace P. Mullin, Diversity, Social Goods Provision, and Performance in the Firm, September 2010

3172 Silvia Dominguez-Martinez, Randolph Sloof and Ferdinand von Siemens, Monitoring your Friends, not your Foes: Strategic Ignorance and the Delegation of Real Authority, September 2010

3173 Marcus Dittrich and Beate Schirwitz, Union Membership and Employment Dynamics: A Note, September 2010

3174 Francesco Daveri, Paolo Manasse and Danila Serra, The Twin Effects of Globalization - Evidence from a Sample of Indian Manufacturing Firms, September 2010

3175 Florian Blöchl, Fabian J. Theis, Fernando Vega-Redondo and Eric O’N. Fisher, Which Sectors of a Modern Economy are most Central?, September 2010 
3176 Dag Morten Dalen, Marilena Locatelli and Steinar Strøm, Longitudinal Analysis of Generic Substitution, September 2010

3177 Armin Falk, Stephan Meier and Christian Zehnder, Did we Overestimate the Role of Social Preferences? The Case of Self-Selected Student Samples, September 2010

3178 Christian Fahrholz and Cezary Wójcik, The Bail-Out! Positive Political Economics of Greek-type Crises in the EMU, September 2010

3179 Klaus Abberger and Wolfgang Nierhaus, The Ifo Business Cycle Clock: Circular Correlation with the Real GDP, September 2010

3180 Walter Krämer and Gerhard Arminger, "True Believers" or Numerical Terrorism at the Nuclear Power Plant, September 2010

3181 Bernard M.S. Van Praag, Dmitri Romanov and Ada Ferrer-i-Carbonell, Happiness and Financial Satisfaction in Israel. Effects of Religiosity, Ethnicity, and War, September 2010

3182 Dimitrios Koumparoulis and Paul De Grauwe, Public Capital, Employment and Productivity: An Empirical Investigation for Greece, September 2010

3183 John Whalley and Tanmaya Shekhar, The Rapidly Deepening India-China Economic Relationship, September 2010

3184 Andreas Schäfer and Thomas Steger, History, Expectations, and Public Policy: Economic Development in Eastern Germany, September 2010

3185 Thomas Eichner and Marco Runkel, Subsidizing Renewable Energy under Capital Mobility, September 2010

3186 Konstantinos Angelopoulos and James Malley, Fear of Model Misspecification and the Robustness Premium, September 2010

3187 Philip E. Graves, A Note on the Design of Experiments Involving Public Goods, September 2010

3188 Glenn Ellison, How does the Market Use Citation Data? The Hirsch Index in Economics, September 2010

3189 Barbara Hanel and Regina T. Riphahn, The Employment of Mothers - Recent Developments and their Determinants in East and West Germany, September 2010

3190 Alexander Haupt and Silke Uebelmesser, Integration, Mobility, and Human Capital Formation, September 2010

3191 Vincenzo Galasso and Paola Profeta, When the State Mirrors the Family: The Design of Pension Systems, September 2010 
3192 Stéphane Zuber and Geir B. Asheim, Justifying Social Discounting: The RankDiscounted Utilitarian Approach, September 2010

3193 Alexander Kemnitz, Educational Federalism and the Quality Effects of Tuition Fees, September 2010

3194 Claudia M. Buch, Sandra Eickmeier and Esteban Prieto, Macroeconomic Factors and Micro-Level Bank Risk, September 2010

3195 May Elsayyad and Kai A. Konrad, Fighting Multiple Tax Havens, September 2010

3196 Laszlo Goerke and Markus Pannenberg, Trade Union Membership and Dismissals, September 2010

3197 Ferdinand Mittermaier and Johannes Rincke, Do Countries Compensate Firms for International Wage Differentials?, September 2010

3198 John Boyd, Gianni De Nicoló and Abu M. Jalal, Bank Competition, Asset Allocations and Risk of Failure: An Empirical Investigation, September 2010

3199 Guido Heineck and Bernd Süssmuth, A Different Look at Lenin's Legacy: Trust, Risk, Fairness and Cooperativeness in the two Germanies, September 2010

3200 Ingvild Almås, Tarjei Havnes and Magne Mogstad, Baby Booming Inequality? Demographic Change and Earnings Inequality in Norway, 1967-2000, October 2010

3201 Thomas Aronsson and Sören Blomquist, The Standard Deviation of Life-Length, Retirement Incentives, and Optimal Pension Design, October 2010

3202 Thorvaldur Gylfason and Eduard Hochreiter, Growing Together: Croatia and Latvia, October 2010

3203 Ken Burdett and Melvyn Coles, Tenure and Experience Effects on Wages: A Theory, October 2010

3204 Wendy Carlin, Good Institutions are not enough: Ongoing Challenges of East German Development, October 2010

3205 Tobias König and Andreas Wagener, Tax Structure and Government Expenditures under Tax Equity Norms, October 2010 